\title{
Die Gründe von Straßenerneuerungen im Spiegel lateinischer Inschriften auf Meilensteinen
}

\author{
Razlogi za obnovo cest \\ v luči latinskih napisov na miljnikih
}

Ulrike EHMIG

Izvleček

V nasprotju s prejšnjimi študijami, v katerih so bili miljniki obravnavani predvsem kot natančen vir za datiranje titulatur rimskih cesarjev in za preučevanje njihove gradbene dejavnosti, pa tudi vir za rekonstrukcijo cestnega omrežja, je avtorica podatke z miljnikov uporabila za primerjalno analizo na višji ravni. Namenom njene raziskave je ustrezalo 250 latinskih napisov na analiziranih miljnikih, pri tem pa se je osredotočila zlasti na izraze, ki navajajo razloge za obnovo cest. Izluščila je številne epigrafske formulacije v splošni rabi ("epigraphic habit") - formulacije v napisih na miljnikih, njihove datacije in posamezni ukrepi, ki so bili sprejeti po nastali škodi, se namreč razlikujejo od območja do območja. Rezultati analize so predstavljeni v obliki obsežnih seznamov.

Ključne besede: rimski imperij; latinski napisi; rimski miljniki; obnova cest; "epigrafska formulacija" ("epigraphic habit"); naravni vplivi

\begin{abstract}
[The reasons for road reconstruction reflected in Latin inscriptions on milestones] In contrast to previous studies on milestones, which primarily use them as sources for the titulatures of Roman emperors and their building activities as well as for road courses, the presented contribution pursues a superordinate, comparative perspective. It focuses on the reasons for road reconstruction, which are mentioned in the Latin inscriptions on milestones. For this purpose, 250 inscriptions are relevant. Their analysis enables identifying numerous epigraphic habits. The formulations in question show specificities with regard to the region in which they were used, the dating of the milestones, and the individual measures taken in response to typical damage events. The results are presented in the form of extensive lists.
\end{abstract}

Keywords: Roman Empire; Latin inscriptions; Roman milestones; road reconstruction; epigraphic habit; natural impacts

Die Bedeutung römischer Straßen ist von der altertumswissenschaftlichen Forschung vielfach betont worden, sei es im Hinblick auf ihre Rolle für die Erschließung, Entwicklung und Strukturierung von Regionen, ihre Relevanz für Truppenbewegungen oder für den Transport von Waren und staatlichen Dokumenten. ${ }^{1}$ Notwendigkeit und Nutzen der Verkehrswege aber werden in noch

1 Exemplarisch und jeweils mit weiterer Literatur Pekáry 1968; Radke 1981; Kolb 2000; Mrozewicz 2004; größerem Maße deutlich, wenn ihre Funktionsfähigkeit eingeschränkt oder gar unterbrochen ist. Die Bilder verwüsteter Infrastruktur infolge von Kriegen oder Naturkatastrophen sind in den modernen Medien nahezu täglich präsent. Unter den Naturgewalten sind es vor allem Erdbeben, Lawinen, Starkregen mit daraus resultierenden Sturzbächen und Überflutungen sowie Stürme,

Speidel 2004; Kolb 2004; Kolb 2007; van Tilburg 2007; Kaiser 2011; Fischer, Horn (Hrsg.) 2013; Grewe 2016. 
die durch umher gewehte Gegenstände und umgestürzte Bäume Straßen unpassierbar machen. Entsprechende Ereignisse sind auch für die Antike in unterschiedlichen Quellen gut bezeugt. ${ }^{2}$ Insbesondere von seismischen Aktivitäten und Fluten berichten die antiken Autoren vielfach. Zum einen diskutieren sie die Entstehung solcher Naturgewalten und ihre Erklärung als Ausdruck göttlichen Waltens. Zum anderen haben die Passagen den Charakter von Schadensberichten, die üblicherweise von der Schilderung öffentlicher Hilfsaktionen begleitet werden. Sowohl für die Kaiser wie auch für andere Euergeten boten insbesondere Erdbeben ideale Gelegenheit, ihre liberalitas unter Beweis zu stellen. ${ }^{3}$

Angesichts dieses Befundes überrascht es, dass im Hinblick auf die Unpassierbarkeit von Straßen Erdbeben in den literarischen und dokumentarischen Quellen der römischen Antike keine Rolle spielen. Inschriften, die Gründe für den Renovierungsbedarf von Bauten und Infrastrukturen angeben, sprechen in erster Linie von vetustas und incuria. Werden überhaupt konkretere Angaben gemacht, war hauptsächlich Feuer - meist formuliert mit der Wendung incendio consumptum - für die Zerstörung von Bauten verantwortlich. Danach, und vor allem überliefert aus italischen Inschriften, folgt terrae motus, niemals jedoch im konkreten Zusammenhang mit Straßen, also im Falle der Verwüstung und Wiederinstandsetzung von Infrastruktur. ${ }^{4}$

2 Dem Artikel liegt ein Vortrag zugrunde, der am 12.11.2015 bei der Journées d'études "Prévention et gestion des catastrophes naturelles dans l'Antiquité" in Montpellier gehalten wurde. Agnès Béranger gilt mein Dank für die Einladung. Rudolf Haensch, München, danke ich für eine Durchsicht und Diskussion des Manuskriptes.

3 Stellvertretend zu Überflutungen Newbold 1982; Aldrete 2007, auch Chassignet 2005. Die Forschungsliteratur $\mathrm{zu}$ Erdbeben ist überaus umfangreich, vgl. hier nur in jüngerer Zeit Jones 2014; Force 2015; Jones 2015; Naco del Hoyo 2015; Borsch, Carrara (Hrsg.) 2016.

${ }^{4}$ Die meisten Inschriften, die über Renovierungsgründe von Bauten berichten, enthalten den Begriff conlapsum oder delapsum. Mittels der Epigraphik-Datenbank Clauss / Slaby lassen sich etwas über 450 Zeugnisse mit dem Wortbestandteil -laps- zusammenstellen. Dazu kommen weitere über 40 einschlägige Inschriften mit dem Partizip consumpt-. 87 \% der-laps-Inschriften geben als Grund vetustas, also das Alter des betreffenden Baues, als Grund seines schlechten Zustandes an. Das Ergebnis des Bauverfalls, ruina, wird in weiteren $5 \%$ genannt, in gleichem Umfang machte man incuria für Bauschäden verantwortlich. In $3 \%$, das sind insgesamt 14 Inschriften, die von drei Zeugnissen aus der Provinz Asia abgesehen, alle aus Italien stammen, war hierfür
Die Hauptquellen, die über die Erneuerung von Straßen Aufschluss geben, sind Meilensteine. Was aber sagen diese über die Hintergründe der infrastrukturellen Arbeiten, aus denen sie resultieren? Welche Ursachen für Bau und Erneuerung werden genannt, und wie sind die jeweiligen Informationen zu bewerten? Bisher hat sich die historische Forschung maßgeblich für die in den Inschriften der Meilensteine gebrauchten offiziellen Wendungen und Kaisertitulaturen interessiert. Dabei stellte man fest, dass für ein und dieselben Herrscher in unterschiedlichen Reichsgebieten voneinander abweichende Formulare üblich waren. Eine zentrale Abfassung oder Kontrolle der Texte auf den Meilensteinen schien dementsprechend nicht stattgefunden zu haben. Diskutiert wurde außerdem, inwieweit die Errichtung von Meilensteinen mit überlieferten historischen Ereignissen und großangelegten öffentlichen Bauprojekten in Verbindung gebracht werden kann. ${ }^{5}$

Eine systematische Auseinandersetzung mit den weiteren Informationen, die die Inschriften auf den Meilensteinen bieten, fand hingegen bislang kaum statt. ${ }^{6}$ Dies betrifft insbesondere die Frage nach der Angabe von Gründen für die Erneuerung der Straßen. Sie sind bisher noch nicht zusammengestellt und vergleichend ausgewertet worden. Es fehlt - anschließend an die Beobachtungen zur Kaisertitulatur - eine mehr als Einzelfälle betreffende Auseinandersetzung mit der Frage, ob man überall dieselben standardisierten Formulare antrifft, oder inwieweit individuelle, das heißt mehr oder minder lokal spezifische Wendungen gebraucht wurden. Damit verbunden ist auch die Überlegung, wo und auf welcher institutionellen Ebene der Text der Meilensteine entworfen worden

terrae motus ausschlaggebend. Einzelfälle verzeichnen tempestas, incendium/ignis oder torrentes als Gründe. Der Begriff consumpt- wurde dagegen sehr spezifisch für die Vernichtung durch Feuer gebraucht. Über die Hälfte der einschlägigen Inschriften enthält die Wendung incendio consumptum. Der Rest macht erneut nahezu ausschließlich vetustas für eine Baufälligkeit verantwortlich.

5 Ausführlich Witschel 2002.

6 Vgl. Kolb 2004, die Forschungsstand und -fragen $\mathrm{zu}$ Meilensteinen skizziert. Im Vordergrund steht deren chronologische Verteilung, die Formulare, Längen- und Distanzangaben, ferner die Diskussion um nicht in Form von In- sondern (nicht erhaltenen) Aufschriften gestaltete Angaben sowie um wiederverwendete Stücke. Hier fügen sich auch jüngere einschlägige Beiträge in epigraphischen Handbüchern ein, so beispielsweise Lassère 2007, 917-919; Andreu Pintado 2009, 426-432; Cooley 2012, 159-168; Kolb 2015. 
war. Unklar ist ferner, ob sich im Falle der Nennung von Naturereignissen konkrete Begebenheiten rekonstruieren lassen. Schließlich bleibt die Frage offen, ob die Inschriften eher latente, anhaltende Probleme von Straßenzuständen widerspiegeln oder aber punktuelle Katastrophen und den gezielten, fallspezifischen Umgang mit entsprechenden Phänomenen.

Um eine verlässliche Vorstellung davon $\mathrm{zu}$ gewinnen, ob und welche Gründe für die Wiederherstellung von Straßen in den Inschriften auf römischen Meilensteinen genannt sind, wurden in der Epigraphik-Datenbank Clauss / Slaby Abfragen für die Kombination der Begriffe viam restituit und iter restituit durchgeführt. Das Resultat sind 350 Inschriften, von denen 250 näher Auskunft über die Hintergründe der betreffenden Maßnahmen geben. Ergänzende Abfragen etwa für die Termini corruptus, dilapsus oder dirutus bringen für Straßenbaumaßnahmen keine wesentlich anderen und weiterführenden Informationen. Vielmehr decken sich die Ergebnisse überaus häufig, so dass die in der genannten Weise ermittelten 250 Inschriften überzeugend als Ausgangspunkt der folgenden Beobachtungen und Überlegungen verwendet werden können.

Eine Reihe von Inschriften aus der Cyrenaica nimmt Bezug auf Zerstörungen während des jüdischen Aufstandes in den Jahren 115/117 n.Chr. ${ }^{7}$ Zusätzlich zu jenen Bauinschriften, die Wiederherstellungsmaßnahmen an Gebäuden wie der Basilika, den öffentlichen Bädern, dem Caesareum, sowie vermutlich dem Tempel der Hecate von Cyrene bezeugen, ${ }^{8}$ beziehen sich drei der zehn einschlägigen Zeugnisse mit der Wendung viam quae tumultu Iudaico eversa et corrupta erat restituit auf die Wiederinstandsetzung der Straße von respektive nach Apollonia. ${ }^{9}$ Die betreffenden Inschriften stellen einen der seltenen Fälle dar, in denen Auswirkungen von Konflikten auf die Infrastruktur in dokumentarischen Zeugnissen Niederschlag fanden. Unklar aber bleibt, wie

7 Dazu Fraser 1950; Fuks 1961; Pucci Ben Zeev 2005; zuletzt Gasperini 2010; kurz Strobel 2010, 389 mit 398 Anm. 31.

8 Basilica: AE 1974, 672 (118/119 n.Chr.); balineum: AE 1928, 2 (119 n.Chr.); Caesarum: AE 1974, 670 (118 n.Chr.); SEG XVII 804 (118 n.Chr.) sowie vermutlich $A E$ 1951, 123 und $A E$ 1974, 669 (118 n.Chr.); templum: SEG IX $168=A E$ 1929, 9 (119 n.Chr.); vgl. Ziosi 2010 Nr. II, IV-VI, VIII, X, XI.

${ }^{9} A E$ 1928, 1; AE 1951, 208 sowie $A E$ 1919, $90=S E G$ IX 252 (alle 118 n.Chr.); Ziosi 2010 Nr. I, III, IX. man sich eine via eversa infolge eines tumultus vorstellen muss, welche Maßnahmen so zerstörerisch waren, dass die Straße nicht oder nur mehr bedingt nutzbar war.

Von den skizzierten Inschriften aus der Cyrenaica abgesehen, enthalten drei Viertel der Meilensteine, die die Wendungen viam restituit oder iter restituit aufweisen, die Erläuterungen via vetustate conlapsa oder via vetustate corrupta. Das fortgeschrittene Alter der Straßen war folglich - wie allgemein bei Bauinschriften zu beobachten - der maßgeblich ins Feld geführte Faktor ihres maroden Zustandes. Die betreffenden Zeugnisse wurden nach Zeit und Provenienz in Details verschieden, das heißt chronologisch wie zugleich auch regional typisch formuliert. Sie umspannen dabei ein weites Verbreitungsgebiet von der iberischen Halbinsel über die gallischen Provinzen sowie die Germania superior bis hin nach Pannonien. Eine große Zahl entsprechender Meilensteine ist darüber hinaus aus Sardinien bezeugt. Im Osten treten sie zwischen Kappadokien sowie Bithynien und Pontus auf.

Für die aus dem Jahr 85 n.Chr. aus der Hispania citerior überlieferten Meilensteine ist die Wendung vias vetustate corruptas typisch. Aus dem Jahr 238 n.Chr. stammen aus derselben Region annähernd zwei Dutzend Exemplare mit der Formulierung vias et pontes tempore vetustatis conlapsos. ${ }^{10}$ In Gallien und der Germania superior schrieb vias et pontes vetustate conlapsos oder häufiger auch conlapsas. Die auf das Jahr 213 n.Chr. datierten Meilensteine aus der Gallia Narbonensis sprechen in lokalem Latein von viam vetustate collabsam. In der Pannonia inferior enthalten alle einschlägigen Zeugnisse aus dem Jahr 217/218 n.Chr. die Wendung vias et pontes vetustate corruptas. Dasselbe Formular war auch typisch für eine Reihe von Meilensteinen, die in der Pannonia superior wenig früher, an der Wende vom 2. zum 3. Jh.n.Chr., errichtet worden waren. In der Mitte des 3. Jh.n.Chr. war es dann in der Region üblich, vias et pontes vetustate conlabsas respektive conlapsas $\mathrm{zu}$ formulieren. Der genau gleiche Wortlaut ist ebenfalls charakteristisch für die große Zahl der aus derselben Zeit überlieferten kappadokischen Meilensteine. In Sardinien dagegen enthielten die im gleichen chronologischen Horizont entstandenen Zeugnisse die Wendung viam quae ducit a ... vetustate corruptam. In Pontus et Bithynia war es in den Jahren 114/116 n.Chr. ebenfalls üblich,

10 Statt tempore ist häufiger auch der Ablativ Plural beziehungsweise Genitiv Singular gebraucht. 
viam vetustate corruptam $\mathrm{zu}$ fomulieren (Liste 1). Die häufig provinzweite Verbreitung der Formulare, die zudem - wie die folgenden Beispiele zeigen - bisweilen mit einer Kritik an der Politik der Vorgänger kombiniert ist, legt nahe, dass sie der Zuständigkeit der Statthalter unterlagen, die teilweise kaiserlichen Wortlaut aufgriff. ${ }^{11}$

Im Gebiet der Provinz Africa proconsularis ${ }^{12}$ trifft man auf einen ganz entsprechenden und zugleich nochmals stärker spezifischen Befund. Hier hob man in den allesamt auf das Jahr 237 n.Chr. datierten Inschriften hervor, dass die Straße von Karthago bis zu den Grenzen der Provinz Numidia lange Zeit vernachlässigt worden war. In der Art eines epigraphic habit sprach man dort regelmäßig von longa incuria. ${ }^{13}$ Auf ähnliche Fälle trifft man in Philippi in Makedonien, wo in zwei Inschriften aus dem Jahr 112 n.Chr. die longa intermissio der Straße von Dyrrhachium nach Neapolis beziehungsweise das wenige Kilometer östlich davon gelegene Acontisma für den schlechten Straßenzustand verantwortlich gemacht wurde ${ }^{14}$ (Liste 2).

Die Inschriften auf zwei Meilensteinen aus der Umgebung von Aquileia berichten, welche Auswirkungen eine derart lange Vernachlässigung konkret hatte: via Annia longa incuria neglecta influentibus palustribus aquis eververata. ${ }^{15} \mathrm{Die}$ Via

11 Vgl. dazu und konträr die Argumentation bei Rathmann 2003, 66-67, wo eine städtische Zuständigkeit favorisiert wird.

12 Allgemein zu späten Meilensteinen in der Africa proconsularis Salama 1987.

$13 \mathrm{Zu}$ Beginn des Jahres 238 n.Chr. entwickelte sich der Aufstand der Provinz Africa proconsularis, der nach Kolb 1977 zentral eine Folge des fiskalischen Drucks auf conductores und coloni der kaiserlichen Domänen war. Vielleicht brachten die unmittelbar vorausgehenden, umfangreichen Straßenbaumaßnahmen die Belastbarkeit an ihre Grenzen und waren mit Ausschlag gebend für den Aufstand. Vgl. jüngst Börm 2008 und Haegemans 2010, 131-211.

14 Dazu Haensch 2018, der die Inschriften für eine propagandistische Übertreibung Traians hält, da zumal in Friedenszeiten eine lange Vernachlässigung zentraler Verkehrsachsen wie der via Egnatia kaum vorstellbar sei.

${ }^{15}$ CIL V 7992 = InscrAqu II 2894a = ILS 5860 (Aquileia): viam Anniam longa incuri[a] neglectam influentibus palustrib(us) aquis eververatam et commeantib(us) inviam inter plurima indulgentiar(um) suar(um) in Aquileiens(es) providentissim(us) princeps restituit; CIL V 7992a (p. 1092) = InscrAqu II 2894b (Aquileia): [viam] [Annia]m long(a) incuri[a neglectam in]fluentib(us) palustri[b(us) aquis everve] ratam et [commeantib] us inviam inter [---]. Vgl. Witschel 2002, 339-357 zur Diskussion der Forschung, die Gruppen von Meilensteinen im Gebiet von Aquileia
Annia entlang des Adriabogens war an verschiedenen Stellen durch Wasser aus den angrenzenden Sümpfen unterspült und weggerissen worden. Dieses Gefahrenbild prägte die Strecke latent dauerhaft. Weitere regional- und zeittypische Formulare jedoch ohne detailliertere Angaben zum Grund der Erneuerungsmaßnahmen liegen aus Apulia, Cilicia, Noricum, Palaestina sowie Raetia vor (Liste 3).

Es bleibt eine letzte Gruppe von Inschriften auf Meilensteinen mit Angabe von Gründen für die Instandsetzung der Straßen zu diskutieren: In Numidien trifft man in einem Umkreis von $25 \mathrm{~km}$ auf ein Dutzend Inschriften mit der vergleichsweise komplexen Wendung viam imbribus et vetustate conlapsam cum pontibus restituit. Die betreffenden Steine konzentrieren sich in den Gebieten von Cirta, El Arrouch und Oued Smendou. Vier Inschriften von anderen numidischen Fundorten zeigen dasselbe Formular. Die Wendung viam imbribus et vetustate conlapsam cum pontibus restituit war über mindestens 65 Jahre im Gebrauch. Die frühesten Belege stammen aus der Regierungszeit des Elagabal, 218/219 n.Chr., die spätesten Zeugnisse datieren in die Zeit des Carinus, in das Jahr 283 n.Chr (Liste 4). Dieser lange Zeitraum überrascht angesichts einerseits der Komplexität der Formulierung sowie andererseits der ansonsten beobachteten regionalund zeittypischen Konzentration der Phrasen. ${ }^{16}$ Im Falle der Wendung viam imbribus et vetustate conlapsam cum pontibus restituit war diese also, anders als sonst häufig festzustellen, nicht auf die Regierungszeit eines bestimmten Herrschers oder Statthalters beziehungsweise gar nur eine einzige von ihm initiierte Baumaßnahme beschränkt. Es liegt nahe, die verhältnismäßige Langlebigkeit des Formulars auf seinen spezifischen Inhalt, die Erwähnung von imber als Grund des maroden Straßenzustandes, zurückzuführen. Der Gedanke wird durch ein weiteres Meilensteinformular untermauert, das unwetterartigen Starkregen thematisiert: Insbesondere in Djemila/Cuicul, also etwa $160 \mathrm{~km}$ westlich des Hauptverbreitungsgebietes der Formel viam imbribus et vetustate conlapsam cum pontibus restituit, lautete die gängige Wendung auf Meilensteinen vias torrentibus exhaustas restituit. Bisweilen wurde sie ergänzt durch den Zusatz ac novis munitionibus dilatavit. Das insgesamt ein halbes Dutzend Inschriften umfassende Beispiel war erneut während einer vergleichsweise langen

mit spezifischen Bürgerkriegsereignissen des 3. und 4. Jh.n.Chr. in Verbindung gebracht hatte.

${ }^{16}$ Vgl. hierzu die entsprechenden Differenzen in Liste 1. 
Periode von annähernd 40 Jahren zwischen Caracalla und der kurzen Regierungszeit des Aemilius Aemilianus Ende Sommer 253 n.Chr. in Gebrauch ${ }^{17}$ (Liste 5).

Nimmt man die beiden skizzierten, in $\mathrm{Nu}$ midien üblichen Wendungen imbribus conlapsa und torrentibus exhausta ernst und erachtet sie nicht als austauschbare Gemeinplätze, legt die auffallend lange Dauer ihres Gebrauchs weniger eine Interpretation als Spiegel sporadischer als vielmehr anhaltender und für die Region typischer Naturereignisse nahe. Schon im Kontext der beiden Inschriften der Via Annia wie auch anderer Beispiele, ${ }^{18}$ haben sich Niederschlag im Allgemeinen sowie das Zusammenspiel von spezifischer Topographie und Witterungsbedingungen von Gebieten als entscheidende Faktoren für den Zustand ihrer Straßen dargestellt.

Für Nordafrika kennen wir auch andere Inschriften als jene auf den Meilensteinen, die von Schäden berichten, die durch Niederschläge und Hochwasser verursacht worden waren. In Zaouia Mornag wurde ein Heiligtum der Caelestis vi fluminis zerstört. Seine Verlegung an einen anderen Ort dürfte weniger auf einen einzigen entsprechenden Schadensfall zurückzuführen sein als eher auf eine wiederholte, längerfristige Erfahrung mit den lokalen Bedingungen. ${ }^{19}$

Die Deutung unterstreicht eine weitere Inschrift auf einem Meilenstein, der an der Via Tauri gefunden wurde, die das Taurusgebirge in Höhe der kilikischen Pforte in einer tiefen Schlucht durchquert. Die Inschrift datiert in das Jahr 217 n.Chr. und nennt frequentissimi illuvies, überaus häufige Überschwemmungen, die mit Felsstürzen und zerrissenen Wege einhergingen, als Ursache der Straßenerneuerung. ${ }^{20}$

17 Vgl. Haensch, Mackensen 2011, 278 Anm. 56, dazu schon Salama 1951, 57-58.

18 Vgl. so etwa: viam inundatione aqu(a)e interruptam restituit (212 n.Chr.): CIL X $6876=$ ILS 5859 (Casilinum); [vi]as per fines Ceutro[n] um vi torrentium [ev] ersas exclusis [flu]minibus et in na[tura]lem alveum redu[ctis] [m]olibus plurib[us locis opp]ositis (163 n.Chr.): CIL XII 107 (p. 805) = ILAlp I 54 = ILS 5868 (p. 186) = AE 1996, 981 (Axima); viam fluminis vi abruptam interciso monte restituerunt (163-165 n.Chr.): CIL III 199 (p. 1228) = ILS 5864 (Abila de Lysanias), zu dieser Haensch 2016, 32-33.

${ }^{19}$ ILAfr 345 = AE 1909, 9: Caelesti Aug(ustae) Granianae sacr[um] Voltius Senecio templum vi fluminis ereptum transtulit et a solo fecit idemque dedica[vit].

${ }^{20}$ RRMAM III 3, 165 = AE 2009, 1527 (Tahta Kopru): [viam] Tauri montis fr[equentissi]mis inluvionibus [dirutam
Ein monumentales epigraphisches Zeugnis aus der Nähe von Terracina aus der Regierungszeit des Theoderich dokumentiert ähnliche Maßnahmen: Decius Caecina Mavortius Basilius, ehemaliger Konsul, praefectus urbi Romae und praefectus praetorio Italiae iniitierte jene Maßnahmen, mit denen die Sümpfe, die die Via Appia regelmäßig überfluteten, trockengelegt wurden. Die Wendung per omnes retro principes inundaverant ist zweifellos Teil einer offiziellen Rhetorik, um die Dimension des euergetischen Aktes zum Ausdruck zu bringen. Ungeachtet dessen aber unterstreicht sie, dass witterungsbedingte Phänomene zu jeder Zeit die Hauptrisiken für die Funktionsfähigkeit der Infrastruktur darstellten. ${ }^{21}$

Kehrt man nochmals zu den numidischen Inschriften mit der Formulierung viam imbribus et vetustate conlapsam cum pontibus restituit zurück, bleibt die Frage nach der Bedeutung der Wendung cum pontibus zu klären. Betrafen die Wiederinstandsetzungsarbeiten Straße und Brücken, oder aber wurden die ruinösen Straßen unter anderem mittels der Anlage von Brücken saniert? Schaut man für diese Überlegung nochmals auf die eingangs genannten 350 Inschriften, die Bauarbeiten an römischen Straßen durch den Gebrauch der Wendung viam restituit und iter restituit bezeugen, lässt sich folgendes festhalten: Die große Mehrzahl der einschlägigen epigraphischen Zeugnisse gebraucht die Wendung vias et pontes restituit. Sie war geläufig auf der iberischen Halbinsel, in den gallischen und germanischen Provinzen, in Rätien und dem Donauraum sowie im östlichen Teil des Imperium Romanum in Palaestina, Kilikien und Kappadokien. ${ }^{22}$ Lediglich in der Pannonia superior trifft man auf eine Handvoll Meilensteine, deren Inschriften die Wendung vias vetustate conlapsas cum pontibus restituit beinhalten. ${ }^{23}$ Sie unterscheiden

ac cae]sis rupibus ac dilat[atis itineri]bus cum pontibus [institutis restit]utam perfece[runt].

21 CIL X $6850=6851=I L C V 35(\mathrm{em})=.I L S 827$ (507-511), vgl. dazu Eck 2004, 20; Haensch, Mackensen 2011, 275-276.

22 Vgl. die Zeugnisse in den Listen 1-3.

23 Vias vetustate conlapsas cum pontibus restituit (244-247 n.Chr.): AE 1996, 1249 (Arrabona); vias vetustate conlabsas(!) cum pontibus restituit (238 n.Chr.): AE 1994, 1395 (Azaum); vias vetusta[te con]lap[sa]s cum ponti[b(us) res]titu[er(unt)] (244-249 n.Chr.): CIL III 11326 (Brigetio); vias cum pon[t(ibus) vetusta]te conlabs(as)(!) res[tituit] (238 n.Chr.): CIL III 11327 (Brigetio); vias ve(t)ustate conlabsas(!) cum pontibus restituit (242-244/269 n.Chr.): CIL III 11333 (Brigetio). 
sich ansonsten formal wie inhaltlich allerdings nicht von der in der Region fünfmal häufiger bezeugten Wendung vias et pontes restituit. Die betreffenden Meilensteine sind also nicht an einem spezifischen Ort konzentriert oder definieren eine zeitlich geschlossene, zum Beispiel frühe oder späte Gruppe.

Der Befund in Numidien dagegen weicht von der skizzierten Beobachtung grundlegend ab. Dort gebrauchte man niemals die Wendung vias et pontes restituit, sondern formulierte immer vias cum pontibus restituit. Man könnte dies überzeugend mit einem regionalen epigraphic habit erklären, einer für die Gegend typischen Sprachform. Jedoch legen die Inschriften der Via Tauri mit der überaus ähnlichen Wendung viam cum pontibus institutis restituit eher ein zeitlich und regional übergeordnetes Verständnis und eine Deutung der Wendung im Sinne einer Konstruktion von Brücken nahe. ${ }^{24}$ Folgt man diesem Gedanken, lässt er sich zudem mit anderen Beobachtungen in Einklang bringen: Aus römischer Zeit sind Sumpfbrücken, deren Tradition bis ins Neolithikum zurückreicht, archäologisch gut bezeugt. Ein gut dokumentiertes Beispiel findet sich in Südhessen: Die Straße, die Dieburg, den Hauptort der civitas Auderiensium im Hinterland des obergermanischen Limes, mit dem Rhein verbindet, quert ein Feuchtareal. Auf einer Länge von $300 \mathrm{~m}$ entdeckte man bei Ausgrabungen die Reste von mindestens 300 Eichenpfählen, die je in Reihen zu drei Exemplaren angeordnet waren. Der Abstand der drei Pfosten zueinander betrug jeweils rund drei Meter, so dass die Gesamtbreite der Trasse mit neun Metern zu rekonstruieren ist. Nach dendrochronologischen Indizien wurde das Holz für die Konstruktion im Jahr 119 n.Chr. geschlagen. ${ }^{25}$ Vor dem Hintergrund solcher, ar-

24 [viam] Tauri montis fr[equentissi]mis inluvionibus [dirutam ac cae]sis rupibus ac dilat[atis itineri]bus cum pontibus [institutis restit] utam perfece[runt] (217 n.Chr.): RRMAM III 3, 165 = AE 2009, 1527 (Tahta Kopru); viam Tauri vetustate [conl]apsam conplanatis monti[bus e] t caesis rupibus ac dilata[tis i]tineribus cum pontibus institutis restituit (217 n.Chr.): IK LV 1, $132=$ RRMAM I $61=$ II 1 , 26 = III 3, $166=A E 1969 / 70,607$ (Tyana).

${ }^{25}$ Zum Befund noch immer grundlegend Geyer et al. 1977. Eine Zusammenstellung archäologischer Zeugnisse präventiven Hochwasserschutzes in antiken Siedlungen gibt Allinne 2007; für das antike Griechenland siehe Fantasia 1999. Zu Sedimentuntersuchungen im nördlichen Tunesien und der Frage geomorpher und klimatischer Veränderungen vgl. Faust et al. 2004; zahlreiche entsprechende Arbeiten wurden in Nordafrika in den vergangenen Jahrzehnten unter der Leitung von Jean Louis Ballais, Aix-en-Provence, durchgeführt, stellvertretend Ballais 1995. chäologisch gut fassbarer Konstruktionen, ist es denkbar, das die Formulierung vias vetustate conlapsas cum pontibus restituit in den Inschriften der (numidischen) Meilensteile als epigraphische Umschreibung derartiger Baumaßnahmen, die die Form von Sumpfbrücken annehmen konnten, gebraucht wurde. ${ }^{26}$ Für die Untermauerung der These wäre die Beobachtung des gemeinsamen Auftretens einer einschlägigen cum pontibus-Inschrift und einer entsprechenden baulichen Konstruktion, wohl verhältnismäßig lange aber wenig hohe Brücken, ${ }^{27}$ notwendig. Dass die inschriftlichen Zeugnisse in großem Maße vor allem aus Numidien vorliegen, könnte mit ihrer Selten- und Besonderheit in dieser Region erklärt werden. In diesem Falle hätten die eher ungewöhnlichen Konstruktionen in spezifischen Formularen in den Inschriften der Meilensteine Niederschlag gefunden.

\section{Zusammenfassung}

Die lateinischen Inschriften auf römischen Meilensteinen wurden bisher vor allem als präzis datierte Quellen für die Titulaturen römischer Herrscher und deren infrastrukturellen Bautätigkeiten sowie für die Rekonstruktion von Straßenverläufen herangezogen. Der vorgelegte Beitrag verfolgte eine andere, übergeordnete und vergleichende Perspektive. Er fokussiert auf die Gründe für die Erneuerung von Straßen, die in den lateinischen Inschriften auf den Meilensteinen erwähnt werden. Basis hierfür sind 250 Inschriften, die die Wendungen viam restituit oder iter restituit enthalten. Ihre Analyse erlaubt es, zahlreiche epigraphic habits zu identifizieren. In drei von vier Fällen wird das fortgeschrittene Alter der Straßen (vetustas) für ihren maroden Zustand verantwortlich gemacht. Die fraglichen Formulierungen zeigen Besonderheiten in Abhängigkeit von der Region, in der sie verwendet wurden, der Datierung der betreffenden Meilensteine und den einzelnen Maßnahmen, die als Reaktion auf typische Schadensereignisse ergriffen wurden. Besonders auffällig ist ein Befund des 3. Jh.n.Chr. in Numidien: Dort wurden über einen

${ }^{26}$ Eine erste eingehende Auseinandersetzung mit den klimatischen Gegebenheiten im antiken Nordafrika bei Gsell 1913, 40-99. Zuletzt hat Leveau 2016 aus archäologischhistorischer Sicht einen aktuellen Überblick über die Forschungssituation und die Frage der sozialen Auswirkungen des Klimas im antiken Nordafrika gegeben.

${ }^{27}$ Vgl. so die Abbildungen bei Salama 1951, Pl. VII-VIII. 
Zeitraum von mindestens 65 Jahren imber et vetustas als Renovierungsgründe von Straßen angeführt. Die Wendung scheint, wie es eine Reihe weiterer Inschriften nahelegt, für die Region typische, die Infrastruktur immer wieder bedrohende Naturereignisse widerzuspiegeln. Vor diesem Hintergrund wird

Zu den Abkürzungen von Inschriftencorpora in den Anmerkungen und Listen vgl. die Angaben in der EDCS / Za okrajšave temeljnih objav napisov v opombah in seznamih glej epigrafsko zbirko EDCS

= Epigraphik-Datenbank Clauss / Slaby (Katholische Universität Eichstätt-Ingolstadt). http://db.edcs.eu/epigr/ hinweise/abkuerz.html [letzter Aufruf 22.10.2020].

ALDRETE, G. S. 2007, Floods of the Tiber in ancient Rome. - Baltimore.

ALLINNE, C. 2007, Les villes romaines face aux inondations. La place des données archéologiques dans l'étude des risques fluviaux. - Géomorphologie: relief, processus, environnement 1, 67-84.

ANDREU PINTADO, J. 2009, Tituli operum publicorum. In: J. Andreu Pintado (Hrsg.), Fundamentos de epigrafía latina, 397-464, Madrid.

BALLAIS, J. L. 1995, Conquêtes et dégradation du milieu au Maghreb oriental pendant l'Antiquité et le Moyen Age. - In: S. van der Leeuw (Hrsg.), L'homme et la dégradation de l'environnement. Actes des XVe rencontres internationales d'archéologie et d'histoire d'Antibes, 20-22 octobre 1994, 331-344, Juan-les-Pins.

BÖRM, H. 2008, Die Herrschaft des Kaisers Maximinus Thrax und das Sechskaiserjahr 238. Der Beginn der "Reichskrise"? - Gymnasium 115, 69-86.

BORSCH, J., L. CARRARA (Hrsg.) 2016, Erdbeben in der Antike. Deutungen - Folgen - Repräsentationen. Proceedings of a conference held at the University of Tübingen in March 2014. - Bedrohte Ordnungen 4.

CHASSIGNET, M. 2005, Les catastrophes naturelles et leur gestion dans l'Ab Vrbe condita de Tite-Live. - In: R. Bedon, E. Hermon (Hrsg.), Concepts, pratiques et enjeux environnementaux dans l'Empire Romain, 337-352, Limoges.

COOLEY, A. E. 2012, The Cambridge Manual of Latin Epigraphy. - New York.

ECK, W. 2004, Straßen und ihre Denkmäler. - In: R. Frei-Stolba (Hrsg.), Siedlung und Verkehr im römischen Reich. Römerstraßen zwischen Herrschaftssicherung und Landschaftsprägung. Akten des Kolloquiums zu Ehren von Prof. H. E. Herzig vom 28. und 29. Juni 2001 in Bern, 17-39, Bern.

FANTASIA, U. 1999, Aree marginali nella Grecia antica: paludi e bonifiche. - In: D. Vera (Hrsg.), Demografia, sistemi agrari, regimi alimentari nel mondo antico. Atti del Convegno Internazionale di Studi (Parma 17-19 ottobre 1997), 65-116, Bari. für die dort regelmäßig gebrauchte Formulierung vias cum pontibus restituit eine Interpretation im Sinne von Sumpfbrücken vorgeschlagen, mit deren Hilfe die Straßen wiederinstandgesetzt wurden. Die Ergebnisse der Studie werden in Form von umfangreichen Listen dargestellt.

FAUST et al. 2004 = D. Faust, C. Zielhofer, R. Baena Escudero, F. Diaz del Olmo 2004, High-resolution fluvial record of late Holocene geomorphic change in northern Tunisia: climatic or human impact? - Quaternary Science Reviews 23, 1757-1775.

FISCHER, T., H. G. HORN (Hrsg.) 2013, Straßen von der Frühgeschichte bis in die Moderne. Verkehrswege Kulturträger - Lebensraum. Akten des Interdisziplinären Kolloquiums Köln, Februar 2011, Schriften des Lehrund Forschungszentrums für die antiken Kulturen des Mittelmeerraumes - Centre for Mediterranean Cultures ZAKMIRA 10

FORCE, E. R. 2015, Impact of tectonic activity on ancient civilizations: recurrent shakeups, tenacity, resilience, and change. - Lanham.

FRASER, P. M. 1950, Hadrian and Cyrene. - Journal of Roman Studies 40, 77-90.

FUKS, A. 1961, Aspects of the Jewish Revolt in A.D. 115-117. - Journal of Roman Studies 51, 98-104.

GASPERINI, L. 2010, La rivolta giudaica a Cirene sotto Traiana. Testimonianze epigrafiche e archeologiche. - In: J. Alvar, J. M. Blazquez (Hrsg.), Traiano, 139-153, Roma. GEYER et al. 1977 = W. Geyer, K. Kandt, I. Kokes, H. Schuler 1977, Die römische Sumpfbrücke bei Bickenbach (Kreis Darmstadt). - Saalburg-Jahrbuch 39, 29-41.

GREWE, K. 2016, Urban Infrastructure in the Roman World. - In: G. L. Irby (Hrsg.), A companion to Science, Technology, and Medicine in Ancient Greece and Rome, Vol. II. - Blackwell Companions to the Ancient World, 768-783, Chichester.

GSELL, S. 1913, Histoire ancienne des l'Afrique du Nord. Tome I: Les conditions du développement historique. Les temps primitifs. La colonisation phénicienne et l'empire de Carthage. - Paris.

HAEGEMANS, K. 2010, Imperial authority and dissent. The Roman Empire in AD 235-238. - Studia Hellenistica 47.

HAENSCH, R. 2016, Safety first? CIL III, 128 et la rhétorique de la securitas. - Syria 93, 29-44.

HAENSCH, R. 2018, Le "visage" du gouvernement romain dans la provincia Macedonia. - In: J. Fournier, M.-G. G. Parissakis (Hrsg.), Les communautés du nord égéen au temps de l'hégémonie romaine. Entre ruprtures et continuités, Meletemata 77, 3-18.

HAENSCH, R., M. MACKENSEN 2011, Das tripolitanische Kastell Gheriat el-Garbia im Licht einer neuen spätantiken Inschrift: Am Tag, als der Regen kam. - Chiron 41, 263-286. 
JONES, C. P. 2014, Earthquakes and Emperors. - In: A. Kolb (Hrsg.), Infrastruktur und Herrschaftsorganisation im Imperium Romanum. Akten der Tagung in Zürich 19.-20.10.2012, 52-65, Berlin.

JONES, C. P. 2015, The Earthquake of 26 BCE in Decrees of Mytilene and Chios. - Chiron 45, 101-122.

KAISER, A. 2011, Roman urban street networks. - New York.

KOLB, A. 2000, Transport und Nachrichtentransfer im römischen Reich. - Klio Beihefte N.F. 2.

KOLB, A. 2004, Römische Meilensteine: Stand der Forschung und Probleme. - In: R. Frei-Stolba (Hrsg.), Siedlung und Verkehr im römischen Reich. Römerstraßen zwischen Herrschaftssicherung und Landschaftsprägung. Akten des Kolloquiums zu Ehren von Prof. H. E. Herzig vom 28. und 29. Juni 2001 in Bern, 135-155, Bern.

KOLB, A. 2007, Raumwahrnehmung und Raumerschließung durch römische Straßen. - In: M. Rathmann (Hrsg.), Wahrnehmung und Erfassung geographischer Räume in der Antike, 169-180, Mainz.

KOLB, A. 2015, Communications and Mobility in the Roman Empire. - In: C. Bruun, J. Edmondson (Hrsg.), The Oxford Handbook of Roman Epigraphy, 649-670, Oxford.

KOLB, F. 1977, Der Aufstand der Provinz Africa Proconsularis im Jahr 238 n.Chr. - Historia 26/4, 440-477.

LASSÈRE, J.-M. 2007, Manuel d'épigraphie romaine II. $-{ }^{2}$ Paris.

LEVEAU, P. 2016, L'environnement de l'Afrique dans l'Antiquité. Climat et société, un état de la question. Ikosim 5, 57-75.

MROZEWICZ, L. 2004, Via et Imperium. Strassenbau und Herrschaft in römischer Welt. - In: R. Frei-Stolba (Hrsg.), Siedlung und Verkehr im römischen Reich. Römerstraßen zwischen Herrschaftssicherung und Landschaftsprägung. Akten des Kolloquiums zu Ehren von Prof. H. E. Herzig vom 28. und 29. Juni 2001 in Bern, 345-360, Bern.
NACO DEL HOYO, T. 2015, Ancient disasters and crisis management in classical antiquity. - Oxford.

NEWBOLD, R. F. 1982, The Reporting of Earthquakes, Fires and Floods by Ancient Historians. - The Proceedings of the African Classical Associations 16, 28-36.

PEKÁRY, T. 1968, Untersuchungen zu den römischen Reichsstraßen. - Antiquitas 1/17.

PUCCI BEN ZEEV, M. 2005, Diaspora Judaism in Turmoil, 116/117 CE. Ancient Sources and Modern Insights. - Interdisciplinary Studies in Ancient Culture and Religion 6.

RADKE, G. 1981, Viae publicae Romanae. - Bologna (= RE Suppl. XIII, Stuttgart 1971, 1417-1686).

RATHMANN, M. 2003, Untersuchungen zu den Reichsstraßen in den westlichen Provinzen des Imperium Romanum. Bonner Jahrbücher Beihefte 55.

SALAMA, P. 1951, Les voies romaines de l'Afrique du Nord. - Alger.

SALAMA, P. 1987, Bornes milliaires d'Afrique proconsulaire. Un panorama historique du Bas Empire Romain. - Collection de l'Ecole Française de Rome 101.

SPEIDEL, M. A. 2004, Heer und Straßen - militares viae. - In: R. Frei-Stolba (Hrsg.), Siedlung und Verkehr im römischen Reich. Römerstraßen zwischen Herrschaftssicherung und Landschaftsprägung. Akten des Kolloquiums zu Ehren von Prof. H. E. Herzig vom 28. und 29. Juni 2001 in Bern, 331-344, Bern.

STROBEL, K. 2010, Kaiser Traian, eine Epoche der Weltgeschichte. - Regensburg.

VAN TILBURG, C. 2007, Traffic and congestion in the Roman Empire. - London.

WITSCHEL, C. 2002, Meilensteine als historische Quelle? Das Beispiel Aquileia. - Chiron 32, 325-393.

ZIOSI, F. 2010, Sulle iscrizioni relative alla ricostruzione di Cirene doppo il tumultus Iudaicus, e sul loro contesto. Zeitschrift für Papyrologie und Epigraphik 172, 239-248. 
Liste 1: Vetustas als Grund für die Erneuerung von Straßen: regionaltypische Wendungen (sortiert nach Grund/Provinz, Datierung, Fundort).

Seznam 1: Vetustas kot razlog za obnovo cest: značilne regionalne formulacije (razvrstitev po razlogu/provinci, dataciji, najdišču).

\begin{tabular}{|c|c|c|c|}
\hline Grund & Datierung & Beleg & Fundort \\
\hline \multicolumn{4}{|l|}{ Hispania citerior: vias vetustate corruptas } \\
\hline $\begin{array}{l}\text { [vias vetus] tate corruptas [restituit] pon[t] es } \\
\text { refe[cit] }\end{array}$ & 85 & $A E 1976,299=\operatorname{HEp} 5,1995,287$ & Las Munecas \\
\hline $\begin{array}{l}\text { [vias vetustat]e corr[u]pt[as refecit pon]tes } \\
\text { restit(uit) }\end{array}$ & 85 & $\begin{array}{l}\text { CIL II } 4918=\text { XVII 1, 1, } 250 \\
=\text { MiliariTarrac } 58\end{array}$ & Lucena de Jalon \\
\hline $\begin{array}{l}\text { [vias vetus] tate corruptas [restituit] pon[t]es } \\
\text { refe }[\mathrm{cit}]\end{array}$ & 85 & CIL XVII 1, 1, $215=$ MiliariTarrac 59 & $\begin{array}{l}\text { Puerto de las } \\
\text { Munecas }\end{array}$ \\
\hline $\begin{array}{l}\text { [viam v]etustate corr(uptam) [r] efecit et pontes } \\
\text { r[e]stutuit }\end{array}$ & 96 & CIRPZamora 47 & Zamora \\
\hline [viam vetustate(?)] cor[ruptam(?)] restituit & 97 & $\begin{array}{l}\text { CIL II } 4724=\mathrm{II}^{2} 7, \text { p. } 65 \text { n. } 15 \\
=H E p 4,1994,303\end{array}$ & Corduba \\
\hline vias vetustate corruptas refecit et restituit & 98 & CIL II $4725=\mathrm{II}^{2}$ 7, p. 65 n. 13 & Corduba \\
\hline \multicolumn{4}{|c|}{ Hispania citerior: vias et pontes tempore vetustatis conlapsas } \\
\hline $\begin{array}{l}\text { vias e[t] ponte[s tem]poris vetusta[te] } \\
\text { [c]onlaps[os restit]ueru[nt] }\end{array}$ & $236-238$ & CIL XVII $1,1,204 \mathrm{a}$ & Ampudia \\
\hline $\begin{array}{l}\text { vias et pontes }\{\text { IF }\} \text { temporis vetustate } \\
\text { conl(a)bsos restituere }\end{array}$ & 238 & $\begin{array}{l}\text { CIL II } 4788=\text { MiliariHispanico } 103 \\
=\operatorname{HEp} 7,1997,1175=13,2003 / 04,859\end{array}$ & Aquae Flaviae \\
\hline $\begin{array}{l}\text { vias et pontes tempore vetustatis collaps(os) } \\
\text { restituerunt }\end{array}$ & 238 & $\begin{array}{l}\text { CIL II } 4826=\text { EE VIII 2, p. } 466 \\
=\text { MiliariHispanico } 349\end{array}$ & Aquae Flaviae \\
\hline $\begin{array}{l}\text { vias et pontes temporibus vetustate co(n)lapsos } \\
\text { restitui praeceperun }(\mathrm{t})\end{array}$ & 238 & $\begin{array}{l}\text { CIL II } 4858 \text { (p. 995) } \\
=\text { MiliariHispanico } 446\end{array}$ & Aquae Flaviae \\
\hline $\begin{array}{l}\text { [vias et] pont[es temporibus] } \\
\text { vet[ustate con]lapsos [restituerunt] }\end{array}$ & 238 & HEp 7, 1997, 522 & Aquae Flaviae \\
\hline $\begin{array}{l}\text { vias et pontes in temporibus vetustate } \\
\text { conlapsos restitui praeceperunt }\end{array}$ & 238 & HEp 7, 1997, 542 & Aquae Flaviae \\
\hline $\begin{array}{l}\text { vias e[t] pontes [t]empo[ri]bus vetu[s]tate con[- } \\
\text { lapsos restitu]i } \operatorname{pr}(\mathrm{a}) \mathrm{ec}[\mathrm{ep}] \operatorname{erun}[\mathrm{t}]\end{array}$ & 238 & HEp 7, 1997, $543=A E 1966,218$ & Aquae Flaviae \\
\hline $\begin{array}{l}\text { vias et pontes [temporis] vetustate conlapsos } \\
\text { restitui p[raeceperunt] }\end{array}$ & 238 & MiliariHispanico 108 & Aquae Flaviae \\
\hline $\begin{array}{l}\text { [vias et pontes tempore vetustatis] conlapsos } \\
\text { restituerunt }\end{array}$ & 238 & $\begin{array}{l}\text { MiliariHispanico } 117 \\
=\text { HEp } 12,2002,618\end{array}$ & Aquae Flaviae \\
\hline $\begin{array}{l}\text { vias et pontes in temporibus vevtustate } \\
\text { conlapsos restitui praeceperunt }\end{array}$ & 238 & MiliariHispanico 453 & Aquae Flaviae \\
\hline $\begin{array}{l}\text { vias et pontes }[\mathrm{i}] \mathrm{n} \text { tempor[ib]us vetustate } \\
\text { con[l] apsos rest[i]tui pr(a)eceperunt }\end{array}$ & 238 & MiliariHispanico 460 & Aquae Flaviae \\
\hline $\begin{array}{l}\text { vias et pontes vetustate conlapsos res[titu]i } \\
\text { cura(ve)runt }\end{array}$ & 238 & $\begin{array}{l}\text { MiliariHispanico } 461 \\
=\operatorname{HEp} 13,2003 / 04,481\end{array}$ & Aquae Flaviae \\
\hline $\begin{array}{l}\text { [vias et] pont[es temporibus] vet[ustate con] } \\
\text { lapsos [restituerunt] p[raeceperunt] }\end{array}$ & 238 & MiliariHispanico 468 & Aquae Flaviae \\
\hline $\begin{array}{l}\text { via }[\mathrm{s}] \text { et pontes tempore vetustatis conlapsos } \\
\text { restituerunt }\end{array}$ & 238 & MiliariTarrac 268 & Avellaneda \\
\hline $\begin{array}{l}\text { vias et pontes tempore vetustatis conlapsos } \\
\text { restituerunt }\end{array}$ & 238 & $\begin{array}{l}\text { CIL II } 4756 \text { (p. XLIX, 994) } \\
=\text { EE VIII 2, p. } 456=I L S 490 \\
=\text { MiliariHispanico } 134\end{array}$ & Bracara Augusta \\
\hline $\begin{array}{l}\text { vias[s et po]ntes tempore v[etustati]s conlapsos } \\
\text { res[tit]uerunt }\end{array}$ & 238 & $\begin{array}{l}\text { MiliariHispanico } 15 \\
=\text { HEp } 13,2003 / 04,816\end{array}$ & Bracara Augusta \\
\hline
\end{tabular}




\begin{tabular}{|c|c|c|c|}
\hline $\begin{array}{l}\text { vias [et pon] tes [t] emp(ore) [vetust(atis) } \\
\text { conl(apsos) restituer]unt }\end{array}$ & 238 & $\begin{array}{l}\text { CIL XVII 1, 1, } 156=\text { MiliariTarrac } 104 \\
=A E 1971,201\end{array}$ & Carenses \\
\hline $\begin{array}{l}\text { [vias et pontes temporibus vet]ustate } \\
\text { cor[rupt(as) rest(ituerunt) }\end{array}$ & 238 & $\begin{array}{l}\text { CIL XVII 1, 1, 272 = ILMadrid } 125 \\
=\text { MiliariTarrac } 108=\text { HEp 5, 1995, } 550 \\
=A E 1994,1055\end{array}$ & Cercedilla \\
\hline $\begin{array}{l}\text { vias et pont(es) tempores vetustatis conlaps(os) } \\
\text { restituerunt }\end{array}$ & 238 & $\begin{array}{l}\text { CIL II } 4870=\text { EE VIII 2, p. } 474 \\
=\text { MiliariHispanico } 149\end{array}$ & Fornelos \\
\hline $\begin{array}{l}\text { vias et pontes tempore vetustatis conlapsos } \\
\text { restituerunt }\end{array}$ & 238 & $\begin{array}{l}\text { CIL II } 4886=\text { XVII 1, 1, } 214 \\
=\text { MiliariTarrac } 107\end{array}$ & Gijano \\
\hline $\begin{array}{l}\text { vias et pontes tempora vetustate } \\
\text { co(n)laps(os) restituerunt }\end{array}$ & 236 & $A E$ 1966, 217 & La Trinchera \\
\hline $\begin{array}{l}\text { [vias et pontes] temp[o]re v[etustatis conlapsos } \\
\text { r] estitu[er]unt }\end{array}$ & 238 & $\begin{array}{l}\text { CIL II } 4874=\text { EE VIII 2, p. } 474 \\
=\text { MiliariHispanico } 156\end{array}$ & Ponte de Lima \\
\hline $\begin{array}{l}\text { [---]vias et pon]tes [tempore vetustatis } \\
\text { conlapsos restitueru]nt }\end{array}$ & 238 & $\begin{array}{l}\text { CIL II } 6243=\text { XVII 1, 1, } 3=\text { Miliari- } \\
\text { Tarrac } 102=\text { IRC III } 194=\text { V, p. } 90\end{array}$ & Sarria de Ter \\
\hline [---] conlapsos restituerunt & 238 & IRC II $102=\mathrm{V}$ p. 76 & Vinaixa \\
\hline $\begin{array}{l}\text { vias et pontis in temporibus vetustate } \\
\text { conlap(s)os restitui praec(e)perum }(\mathrm{t})\end{array}$ & 238 & $\begin{array}{l}\text { CIL II } 4853=\text { IRG IV } 32=\text { AquaeFla } \\
\text { viae } 536=\text { MiliariHispanico } 599\end{array}$ & Xinzo de Limia \\
\hline $\begin{array}{l}\text { [vias et p]ontes [temporibus vetustate conlapsos } \\
\text { pra]ec[eperunt] [r] estitu[it] }\end{array}$ & 238 & $\begin{array}{l}\text { MiliariHispanico } 130 \\
=\text { HEp } 13,2003 / 04,727\end{array}$ & Zamora \\
\hline $\begin{array}{l}\text { vias e[t pontes tempo]r(is) vetust(ate) conl[ap(- } \\
\text { sos) restit(uerunt)] }\end{array}$ & 238 & CIL XVII 1, 1, $161=$ MiliariTarrac 106 & $?$ \\
\hline \multicolumn{4}{|c|}{ Alpes Maritimae: viam Iuliam Augustam a flumine Trebia quae vetustate interciderat sua pecunia restituit } \\
\hline $\begin{array}{l}\text { viam Iuliam } \operatorname{Aug}(\text { ustam) a flumine } \operatorname{Treb}\{b\} \text { ia } \\
\text { quae vetustate interciderat sua pecunia restituit }\end{array}$ & $124 / 125$ & $\begin{array}{l}\text { CIL V } 8102=\text { IANice } 159=\text { ILS } 5823 \\
=I L A M 392=A E 2002,900\end{array}$ & Tropaea Augusti \\
\hline $\begin{array}{l}\text { viam Iuliam } \mathrm{A}[\mathrm{ug}(\mathrm{ustam})][\mathrm{a}] \text { flum[i]ne } \mathrm{T}[\mathrm{re}- \\
\text { bia quae] vetustate intercid[erat] sua pecunia } \\
\text { restituit }\end{array}$ & $124 / 125$ & $\begin{array}{l}\text { CIL V } 8103=\text { IANice } 160 \mathrm{~b} \\
=\text { ILAM } 393\end{array}$ & Tropaea Augusti \\
\hline $\begin{array}{l}\text { [via]m Iuliam Aug(ustam) a flumine Trebia } \\
\text { quae vetustate interciderat sua pecunia restituit }\end{array}$ & $124 / 125$ & $\begin{array}{l}\text { CIL V } 8106=\text { IANice } 160 \mathrm{e} \\
=I L A M 396\end{array}$ & Tropaea Augusti \\
\hline \multicolumn{4}{|l|}{ Alpes Maritimae: viam vetustate collapsam restituit } \\
\hline [viam vetustat(e) collaps(am) rest(ituit)] & $212 / 213$ & ILAM $406=$ = AE 1995, 1017 & Vintium \\
\hline viam vetu[s]t(ate) col[1]a[ps]a[m] rest(ituit) & 213 & $\begin{array}{l}\text { CIL XII } 5438 \text { (p. 857) = XVII 2, } 13 \\
=\text { ILAM } 411\end{array}$ & Salinae \\
\hline \multicolumn{4}{|c|}{$\begin{array}{l}\text { Aquitania, Lugdunensis, Gallia Narbonensis, Belgica, Germania superior: } \\
\text { vias et pontes vetustate conlapsas/conlapsos restituit/restituerunt }\end{array}$} \\
\hline vias et pon[tes vetus] tate conl[absas restituit] & $213 ?$ & $\begin{array}{l}\text { CIL XIII } 9054=\text { XVII 2, } 518 \\
=A E 1983,710\end{array}$ & Divodurum \\
\hline $\begin{array}{l}\text { vias [et] pont(es) vetust(ate) conlabsas } \\
\text { res[ti] tuit }\end{array}$ & $213 ?$ & $\begin{array}{l}\text { CIL XIII } 9034=\text { XVII 2, } 513 \\
=\text { ILTG } 487\end{array}$ & Juvigny \\
\hline $\begin{array}{l}\text { ponte[s e]t vias vetust[ate conl]ap[sas] } \\
\text { rest[itu]it }\end{array}$ & 213 & CIL XVII 2, $548=A E$ 1924, 19 & Niederemmel \\
\hline [vias et pontes vetustate] conlab[s]a[s [restituit] & 213 & $A E 1996,1141$ & $\begin{array}{c}\text { Augusta } \\
\text { Rauricorum }\end{array}$ \\
\hline vias et pontes vetustate collabs(os) restitui[t] & 213 & $\begin{array}{l}\text { CIL XIII } 9061=\text { XVII 2, } 126 \\
=\text { RISch III } 318\end{array}$ & Lousonna \\
\hline vias et pont(es) v[etust(ate)] colla[psos res]tituit & 213 & CIL XIII $9068=$ XVII 2, 674 & $\begin{array}{l}\text { Montagny-la- } \\
\quad \text { Ville }\end{array}$ \\
\hline vias et pont(es) vetustate collaps(os) restituit & 213 & CIL XIII 9072 = XVII 2, 666 & Salodurum \\
\hline $\begin{array}{l}\text { [vias et pon]t(es) vetust[ate collaps(os)] res- } \\
\text { tit[uit] }\end{array}$ & 213 & CIL XVII 2, 501 & Urba \\
\hline
\end{tabular}




\begin{tabular}{|c|c|c|c|}
\hline $\begin{array}{l}\text { vias [et pontes vetust(ate) } \\
\text { conlaps(as) ---]po restituer(unt) }\end{array}$ & 237 & $A E 1996,1048$ & Perigne \\
\hline $\begin{array}{l}\text { vias et [po]ntes vetus[tate] conlapsas } \\
\text { [res]titue[runt] }\end{array}$ & 237 & $\begin{array}{l}\text { CIL XIII } 8874=\text { XVII } 2,326 \\
=I L A \text { Vell } 60\end{array}$ & Ruessio \\
\hline vias et pontes vetus[tate conla]psas restituerunt & 237 & CIL XIII $8940=$ XVII 2, 367 & Trouy \\
\hline $\begin{array}{l}\text { [vias et pontes vet]us[tate conlapsos } \\
\text { restituerunt] }\end{array}$ & 237 & $\begin{array}{l}\text { CIL XIII } 8869=\text { XVII } 2,321 \\
=I L A \text { Vell } 58\end{array}$ & $\begin{array}{l}\text { Beaune-sur- } \\
\text { Arzon }\end{array}$ \\
\hline $\begin{array}{l}\text { [vi]as e[t ponte]s v[etus(tate co]nl[apsos } \\
\text { re]st[ituerunt] }\end{array}$ & 237 & $\begin{array}{l}\text { CIL XIII } 8870=\text { XVII } 2,322 \\
=I L A \text { Vell } 59\end{array}$ & $\begin{array}{l}\text { Beaune-sur- } \\
\text { Arzon }\end{array}$ \\
\hline $\begin{array}{l}\text { [vias et pont]us vetustat[e] con[lapsos] } \\
\text { restituerunt }\end{array}$ & 237 & $\begin{array}{l}\text { CIL XIII } 8867=\text { XVII } 2,318 \\
=I L A \text { Vell } 57\end{array}$ & Usson-en-Forez \\
\hline $\begin{array}{l}\text { pontes et vias vetustat(e) conlabs(as) rest(itu- } \\
\text { erunt) }\end{array}$ & $235-238$ & $\begin{array}{l}\text { CIL XII } 5534=\text { XVII 2, } 135 \\
=\text { RISch III } 319\end{array}$ & Prevessin-Moens \\
\hline $\begin{array}{l}\text { pontes et vias vetust(ate) conlabs(os) restit(ue- } \\
\text { runt) }\end{array}$ & $235-238$ & CIL XIII $9058=$ XVII 2, 130 & Dully \\
\hline $\begin{array}{l}\text { vias e[t] pontes vetust(ate) conlabs(os) rest(i- } \\
\text { tuit) }\end{array}$ & $238-244$ & CIL XIII $9057=$ XVII 2, 129 & Dully \\
\hline $\begin{array}{l}\text { vias et pon[tes ve]tust(ate) conla[ps(os) rest(i- } \\
\text { tuit)] }\end{array}$ & 240 & CIL XIII $9059=$ XVII 2, 127 & Lavigny \\
\hline \multicolumn{4}{|c|}{ Gallia Narbonensis: viam vetustate collabsam restituit } \\
\hline$[$ via]m [vetu]s[t]ate $[\mathrm{c}]$ ollabs(am) rest(ituit) & 213 & $\begin{array}{l}\text { CIL XII } 5432(\text { p. 857) = XVII 2, } 8 \\
=\text { ILAM } 409\end{array}$ & Antipolis \\
\hline viam vetustat(e) collabs(am) rest(ituit) & 213 & $\begin{array}{l}\text { CIL XII } 5430(\text { p. 857) = XVII 2, } 7 \\
=\text { ILAM } 407\end{array}$ & Greolieres \\
\hline viam [vetust]at(e) colla[bs(am) rest(ituit) & 213 & $\begin{array}{l}\text { CIL XII } 5431(\text { p. 857) = XVII 2, } 6 \\
=I L A M 408\end{array}$ & Greolieres \\
\hline viam vetustate collabs(am) restituit & 213 & $\begin{array}{l}C I L \text { XII p. } 857=\text { XVII 2, } 17=I L A M \\
414=A E 1978,472=1995,1020\end{array}$ & Senez \\
\hline \multicolumn{4}{|c|}{ Pannonia superior, Pannonia inferior: vias et pontes vetustate corruptas restituerunt } \\
\hline $\begin{array}{l}\text { [vias et p] ontes [vetustate conru]ptas } \\
\text { [restituerunt ?] }\end{array}$ & $\begin{array}{l}\text { Sept. Sev. + } \\
\text { Söhne }\end{array}$ & CIL III $4619=11324=$ ILSlov I 189 & Veliki Podlog \\
\hline via[s vetustat]e conru[ptas restitueru]nt & $198 ?$ & CIL III $15199=A I J 608$ & Dragotina \\
\hline $\begin{array}{l}\text { vias et pon[tes vetusta]te conrupt[as } \\
\text { re]stituerunt }\end{array}$ & 200 & CIL III $4617=11323=$ ILSlov I 186 & $\begin{array}{l}\text { Mačkovski / } \\
\text { Mačkovec }\end{array}$ \\
\hline $\begin{array}{l}\text { [via]s et pont(es) vetust(ate) corrupt(as) rest(i- } \\
\text { tuerunt) }\end{array}$ & 201 & CIL III 4638 & Brigetio \\
\hline $\begin{array}{l}\text { [vi] as et [pon]t[es vetustate corr }] \text { upt(os) rest(i- } \\
\text { tuerunt) }\end{array}$ & 201 & $A E 2010,1251$ & Crumerum \\
\hline $\begin{array}{l}\text { vias et } \mathrm{p}[\mathrm{ont}] \text { es vetustate }[\mathrm{co}] \mathrm{nruptas} \\
\text { restituerunt }\end{array}$ & 201 & CIL III $4622($ p. 1794) = ILSlov I 194 & Krško \\
\hline $\begin{array}{l}\text { [vias et p]ontes [vetustate co]rrupt[as } \\
\text { restit]uerunt }\end{array}$ & 201 & CIL III 4623 (p. 1794) = ILSlov I 200 & Mokrice \\
\hline $\begin{array}{l}\text { [vias et p]ontes [vetustate corr] uptas } \\
\text { [restituerunt] }\end{array}$ & 201 & AE 2006, 1032 & Neviodunum \\
\hline $\begin{array}{l}\text { vias et pontes vetustate conruptas } \\
\text { restituerunt }\end{array}$ & 201 & CIL III $4624=11321=$ ILSlov I 199 & Brežice \\
\hline $\begin{array}{l}\text { vias et pontes vetustate corrup[[[tas } \\
\text { restitu]]]er(u)nt }\end{array}$ & $217 / 218$ & CIL III 10647 & Ad Militare \\
\hline
\end{tabular}




\begin{tabular}{|c|c|c|c|}
\hline $\begin{array}{l}\text { vias et po[ntes] vetusta[te] cor[ruptas] resti- } \\
\text { tu[e]ru[nt] }\end{array}$ & $217 / 218$ & CIL III 3720 & Aquincum \\
\hline $\begin{array}{l}\text { [vias et pontes ve]tus[tate corruptas } \\
\text { restituerunt] }\end{array}$ & $217 / 218$ & CIL III $4636=10658$ & Aquincum \\
\hline $\begin{array}{l}{[[\mathrm{v}[\mathrm{i}] \text { as et } \mathrm{p}]] \text { ontes vetustate conrupt }[\text { as }} \\
\mathrm{r}] \mathrm{e}[\mathrm{s}] \text { tituerunt }\end{array}$ & $217 / 218$ & CIL III 10629 & Aquincum \\
\hline vias et pontes vetustate corruptas restituerunt & $217 / 218$ & CIL III 14354,3 & Aquincum \\
\hline vias et pontes vetustate conruptas restitue[r]unt & $217 / 218$ & CIL III 10644 & Bolcske \\
\hline $\begin{array}{l}\text { [via]s ft pon[tes vetust]ate gorrdu[tas] re[stitu- } \\
\text { erunt] }\end{array}$ & $217 / 218$ & CIL III $6467=10618$ & Buda-Uljak \\
\hline vias et pontes vetustate corrupta[s restitueru]nt & $217 / 218$ & CIL III 10637 & Intercisa \\
\hline vias et pontes vetustate corruptas restitue[runt] & $217 / 218$ & $A E 1953,11$ & Racalmas \\
\hline vias et pontes vetustate corruptas restituerunt & $217 / 218$ & $A E 1980,716$ & Racalmas \\
\hline vias et pontes vetustate corruptas restituer $[\mathrm{u}] \mathrm{nt}$ & $217 / 218$ & CIL III $3726=10635$ & $\begin{array}{l}\text { Szalkszentmar- } \\
\text { ton }\end{array}$ \\
\hline $\begin{array}{l}\text { vias et po[ntes vet]usta[te] conruptas re[sti- } \\
\text { tuer(unt)] }\end{array}$ & $217 / 218$ & CIL III 3724 (p. 1717) & Titel \\
\hline $\begin{array}{l}\text { [vias] et pon }[\mathrm{t}] \text { es [vetu] stat }[\mathrm{e}] \text { corruptas } \\
\text { [restitue]r[unt] }\end{array}$ & $217 / 218$ & CIL III 3725 & Titel \\
\hline \multicolumn{4}{|c|}{ Pannonia superior: vias vetustate conlapsas cum pontibus restituit } \\
\hline vias vetustate conlabsas cum pontibus restituit & 238 & $A E 1994,1395$ & Azaum \\
\hline $\begin{array}{l}\text { vias cum pon[t(ibus) vetusta]te conlabs(as) } \\
\text { res[tituit] }\end{array}$ & 238 & CIL III 11327 & Brigetio \\
\hline $\begin{array}{l}\text { vias ve(t)ustate conlabsas cum pontibus } \\
\text { restituit }\end{array}$ & $242-244$ & CIL III 11333 & Brigetio \\
\hline vias vetustate conlapsas cum pontibus restituit & $244-247$ & $A E 1996,1249$ & Arrabona \\
\hline $\begin{array}{l}\text { vias vetusta[te con]lap[sa]s cum ponti[b(us) } \\
\text { res]titu[er(unt)] }\end{array}$ & $244-249$ & CIL III 11326 & Brigetio \\
\hline \multicolumn{4}{|c|}{ Pannonia superior, Dalmatia, Asia, Cappadocia: vias et pontes vetustate conlapsas restituit/restituerunt } \\
\hline vias et pontes vetustate conlabsos restituerunt & 218 & $A E 1996,1248$ & Arrabona \\
\hline $\begin{array}{l}\text { vias et pontes vetustate (con)labs(as) } \\
\text { restituerunt }\end{array}$ & $236-238$ & CIL III $4630=11339$ & Solva \\
\hline vias et pontes vetustate conlabs(as) restit(uit) & 238 & CIL III 4644 & Schwechat \\
\hline $\begin{array}{l}\text { [via]s vetust[ate conlap]s(as) cum [pontibus } \\
\text { rest]ituit }\end{array}$ & $238-244$ & CIL III $11332=$ IPSSTA 4 & Virth \\
\hline $\begin{array}{l}\text { [vias] vetu[s] tate conla[psas cum pontibus } \\
\text { restituit] }\end{array}$ & $244 ?$ & CIL III 11337 & Dorog \\
\hline $\begin{array}{l}\text { vias et ponte(s) vetustate conlabs(as) } \\
\text { restituerunt }\end{array}$ & 244 & CIL III $4627=11334$ & Sutto \\
\hline $\begin{array}{l}\text { vias et po[nte]s vetustate con[lap]s(as) restitu- } \\
\text { e(runt) }\end{array}$ & $244-247$ & CIL III 4626 & Sutto \\
\hline $\begin{array}{l}\text { vias et pont(es) ve(tustate) conl(apsas) resti- } \\
\text { tu[it] }\end{array}$ & 249 & CIL III 4651 & Inzersdorf \\
\hline pon[tes et vias conlabsas vetu]st(ate) rest(ituit) & 250 & CIL III 4645 & Schwechat \\
\hline $\begin{array}{l}\text { po[ntes et vias] vetus[tate conlaps(as)] rest[i- } \\
\text { tuit] }\end{array}$ & $251 / 253$ & $A E 1973,430$ & Carnuntum \\
\hline vias et pontes vetusta(te) conlabsas restituit & $256-258$ & CIL III $4652=$ ILS 555 & Inzersdorf \\
\hline $\begin{array}{l}\mathrm{v}[\mathrm{i}] \mathrm{a}[\mathrm{s}] \text { et pontes vetusta(te) conlapsa(s) resti(- } \\
\text { tuit) }\end{array}$ & $256-258$ & CIL III 4647 & Vindobona \\
\hline vias et pontes vetust(ate) conlabsas restit(uit) & 257 & CIL III 4646 & Schwechat \\
\hline
\end{tabular}




\begin{tabular}{|c|c|c|c|}
\hline $\begin{array}{l}\mathrm{v}[\mathrm{i}] \mathrm{a}[\mathrm{s} \text { mi }] \operatorname{liar}[\mathrm{ia} \mathrm{p}] \mathrm{o}[\mathrm{n}] \mathrm{t}[\mathrm{e}] \mathrm{s} \text { vetus[t]a[s} \\
\text { rest(it)]uerunt }\end{array}$ & 257 & AIJ $600=I L J u g$ I 361 & Ormož \\
\hline vi[as et pontes vetustate conlapsas restituerunt] & $253-260$ & CIL III $14333,9=$ XVII 4, 2, 240 & Burnum \\
\hline $\begin{array}{l}\text { [vias et pon]t[es vetustate co]n[1]aps[as } \\
\text { resti] tu[er]unt }\end{array}$ & $?$ & $\begin{array}{l}\text { CIL III } 12184=\text { RRMAM II } 1,797 \\
=\text { III } 3,108 \mathrm{q}\end{array}$ & Lystra \\
\hline [vias et pontes] vetustate $c$ [onlapsas] restituit & $216 / 217$ & $\begin{array}{l}\text { RRMAM II } 1,821=\mathrm{III} 3,114 \\
=A E 1986,690=1990,982\end{array}$ & Arabissus \\
\hline vias et pontes vet $\{\mathrm{t}\}$ ustate $[\mathrm{co}]$ nlapsas rest $[\mathrm{itu}]$ it & $218-222$ & $\begin{array}{l}C I L \text { III } 6906=12169 \\
=R R M A M \text { II } 1,779=\text { III } 3,118 \mathrm{c}\end{array}$ & Arabissus \\
\hline vias et pontes vet $\{\mathrm{t}\}$ usta[te co]nlapsas restituit & $218-222$ & $\begin{array}{l}\text { CIL III } 6939=12187 \\
R R M A M \text { II } 1,755=\text { III } 3,104 \mathrm{f}\end{array}$ & Cucusus \\
\hline vias et pontes vetustate conlapsas restituerunt & $218-305$ & $\begin{array}{l}C I L \text { III } 6918-6920=R R M A M \text { II } 1, \\
792=\text { III } 3,1081=A E 1888,183\end{array}$ & Kanlikavak \\
\hline vias et pontes vetustate conlapsas restituit & 222 & RRMAM II $1,505=$ III $3,68 \mathrm{a}$ & Alisli Burun \\
\hline vias et pontes vet $\{\mathrm{t}\}$ ustate conlapsas restituit & 222 & RRMAM II 1, $719=$ III 3, 119a & Cagilhan \\
\hline vias et pontes vetustate conlapsas restituit & 222 & RRMAM II $1,526=$ III $3,72 \mathrm{e}$ & Degirmentas \\
\hline vias et [pont]es vetu[state co]nlapsas [restitu] it & 222 & RRMAM II $1,15=$ III 3, 76 & Elemanli \\
\hline via[s] et po[n] tes vetostate conlapsas restitu(i)t & 222 & $\begin{array}{l}\text { CIL III } 6954=12211 \\
=\text { RRMAM II } 1,545=\text { III } 3,87 \mathrm{a}\end{array}$ & Hierapolis \\
\hline vias et pontes vetustate conlapsas restituit & 222 & RRMAM II $1,538=$ III $3,75 \mathrm{~h}$ & Imirzaga \\
\hline [vias et pontes vetus] tate conlaps[a]s restituit & $222-235$ & RRMAM II $1,518=$ III $3,70 c$ & Degirmentas \\
\hline $\begin{array}{l}\text { vias } \mathrm{e}(\mathrm{t}) \text { pontes vetustate cunlapsas }\{\text { asas }\} \\
\text { res[ti]tuerunt }\end{array}$ & $236-238$ & $\begin{array}{l}\text { RRMAM II } 1,858=\text { III } 3,2 \\
=A E 1977,814\end{array}$ & Belkuyu \\
\hline $\begin{array}{l}\text { [vias] et pontes vet[us]tate conlapsas } \\
\text { restituerunt }\end{array}$ & $236-238$ & $R R M A M$ II $1,722=$ III $3,94 \mathrm{a}$ & Haydan \\
\hline vias et pontes vetustate conlabsas restituerunt & $236-305$ & $\begin{array}{l}\text { CIL III } 6933=\text { RRMAM II } 1,752 \\
=\text { III } 3,104 \mathrm{c}\end{array}$ & Cucusus \\
\hline vias et pontes vetustate conlabsas res[tit]uerunt & $236-238$ & $R R M A M$ II $1,563=$ III $3,85 \mathrm{~d}$ & Mollahuseyin \\
\hline vias et pontes vetustate conlapsas restituit & 238 & RRMAM II 1, $515=$ III 3, 91 & Hierapolis \\
\hline $\begin{array}{l}{[\mathrm{v}] \mathrm{i}[\text { as et } \mathrm{p}] \text { ontes }[\mathrm{v}] \mathrm{et}[\mathrm{u}] \text { state conlapsas }} \\
\text { restituerunt }\end{array}$ & $244-247$ & $R R M A M$ II $1,508=$ III $3,68 \mathrm{~d}$ & Alisli Burun \\
\hline vias et pontes vetustate conlapsas restituerunt & $244-247$ & RMMAM II 1, $720=$ III 3, 119b & Cagilhan \\
\hline $\begin{array}{l}{[\text { vias et } \mathrm{p}] \mathrm{o}[\text { ntes vetustate }] \text { conl }[\mathrm{a}] \mathrm{psa}[\mathrm{s}} \\
\text { restitueru]nt }\end{array}$ & $244-247$ & $\begin{array}{l}\text { CIL III } 12192=\text { RRMAM II } 1,764 \\
=\text { III 3, 106a }\end{array}$ & Cucusus \\
\hline $\begin{array}{l}\mathrm{v}[\text { ias et pontes v] etusta[te conlaps] as } \\
\text { resti[tu]eru[nt] }\end{array}$ & $244-247$ & RRMAM II $1,724=\mathrm{III} 3,94 \mathrm{c}$ & Haydan \\
\hline $\begin{array}{l}\text { vias e[t p] ontes ve }[\mathrm{tu}] \text { state conl[a]psas } \\
\mathrm{r}[\mathrm{e}] \mathrm{st}[\mathrm{i}] \mathrm{t}[\mathrm{u}] \text { erunt }\end{array}$ & $244-247$ & $\begin{array}{l}\text { CIL III } 6947=\text { RRMAM II } 1,570 \\
=\text { III } 3,93 \mathrm{a}\end{array}$ & Hierapolis \\
\hline $\begin{array}{l}\text { via[s et po]ntes v[etust]ate conla[ps]as } \\
\text { restituerunt }\end{array}$ & $244-247$ & $\begin{array}{l}\text { CIL III } 12199=\text { RRMAM II } 1,553 \\
=\text { III } 3,89 \mathrm{c}\end{array}$ & Hierapolis \\
\hline $\begin{array}{l}\text { vi]a[s] e[t] pont[e]s v[etust]ate [con]lapsas } \\
\text { restitu[erunt] }\end{array}$ & $244-247$ & $\begin{array}{l}\text { CIL III } 12206=R R M A M \text { II } 1,547 \\
=\text { III } 3,88 \mathrm{a}\end{array}$ & Hierapolis \\
\hline $\begin{array}{l}\text { vias et pontes vet[ustat]e conlapsa[s } \\
\text { restitu] erunt }\end{array}$ & $244-247$ & RRMAM III 3, 93g & Hierapolis \\
\hline $\begin{array}{l}\text { vias et [pontes] vetusta[te conlapsas] restitu[e- } \\
\text { runt] }\end{array}$ & $244-247$ & RRMAM II $1,531=$ III $3,75 b$ & Imirzaga \\
\hline $\begin{array}{l}\text { vias et pont }[\mathrm{e}] \mathrm{s} \text { vetustate conlapsas resti- } \\
\text { tuer[un]t }\end{array}$ & $244-247$ & $\begin{array}{l}\text { CIL III } 6914=R R M A M \text { II } 1,781 \\
=\text { III } 3,108 \mathrm{a}=A E 1888,182\end{array}$ & Kanlikavak \\
\hline $\begin{array}{l}\text { [vi]as et pontes vet[ust]ate conlapsas res[titue- } \\
\text { ru]nt }\end{array}$ & $244-247$ & $\begin{array}{l}\text { CIL III } 6946=\text { RRMAM II } 1,806 \\
=\text { III } 3,98 \mathrm{a}\end{array}$ & Siricis \\
\hline
\end{tabular}




\begin{tabular}{|c|c|c|c|}
\hline [vias et] pont[es vetust]ate conlapsas restituerunt & $244-305$ & RRMAM II $1,17=$ III $3,78 \mathrm{~b}$ & Elemanli \\
\hline $\begin{array}{l}\text { vias et pontes vetustate conlapsas } \\
\text { rest[it]ue[r]unt }\end{array}$ & $244-305$ & RRMAM II $1,573=$ III 3, 93d & Hierapolis \\
\hline $\begin{array}{l}\text { vias et ponte[s] vetusta[te co]nlapsas } \\
\text { [resti]tuer[unt] }\end{array}$ & $244-305$ & $\begin{array}{l}C I L \text { III } 6915-6916 \\
=R R M A M \text { II } 1,790=\text { III } 3,108 \mathrm{j}\end{array}$ & Kanlikavak \\
\hline $\begin{array}{l}\text { vias [et] pontes vetus[tat]e conlapsas } \\
\text { r[es]tituer(unt) }\end{array}$ & $244-305$ & $\begin{array}{l}C I L \text { III } 6942-6943 \\
=\text { RRMAM II } 1,818=\text { III } 3,103 \mathrm{~b}\end{array}$ & Mehemet \\
\hline vias et pontes vetustate conlapsas restituerunt & $244-305$ & $\begin{array}{l}C I L \text { III } 6955=12212 \\
=\text { RRMAM II } 1,561=\text { III } 3,85 \mathrm{c}\end{array}$ & Mollahuseyin \\
\hline $\begin{array}{l}\text { vias [et pontes ve]tustate co[nlapsas } \\
\text { res]tituerunt }\end{array}$ & $244-305$ & $\begin{array}{l}C I L \text { III } 6944=12194 \\
=R R M A M \text { II } 1,817=\text { III } 3,103 a\end{array}$ & Siricis \\
\hline $\begin{array}{l}\text { vias] [e]t pontes [vet] ustate con[l]apsas resti- } \\
\text { tu[e]runt }\end{array}$ & $251-253$ & $\begin{array}{l}\text { CIL III } 12196 \\
=\text { RRMAM II } 1,810=\text { III } 3,100 \mathrm{~b}\end{array}$ & Siricis \\
\hline \multicolumn{4}{|l|}{ Galatia: viam vetustate conlapsam restituit } \\
\hline viam vetustate comlalsam $[\mathrm{r}]$ estituit & 222 & $\begin{array}{l}C I L \text { III } 14184,42 \\
=\text { RRMAM II } 1,334=\text { III } 2,58 \mathrm{a}\end{array}$ & Eskiyapar \\
\hline viam vet $\{\mathrm{t}\} \mathrm{u}(\mathrm{s}) \mathrm{t}\{\mathrm{t}\}$ ate conlapsam restituit & $222 / 223$ & RRMAM III 2,62 & Bolatcik \\
\hline \multicolumn{4}{|c|}{ Pontus et Bithynia: viam vetustate corruptam restituit } \\
\hline viam vetustate corru $\{\mathrm{m}\} \mathrm{p}\{\mathrm{a}\}$ tam restituit & $114 / 115$ & $\begin{array}{l}R R M A M \mathrm{I} 8 \mathrm{~b}=I K \mathrm{X} 1002 \\
=A E 1984,830\end{array}$ & Medetli \\
\hline viam vetustate corruptam restituit & $115 / 116$ & TAM IV $1,11=R R M A M I 4$ & Nicomedia \\
\hline viam vetustate corruptam restituit & $115 / 116$ & TAM IV $1,12=R R M A M$ I 2 & Sirin Yalisi \\
\hline \multicolumn{4}{|c|}{ Sardinia: viam quae ducit ... vetustate corruptam restituit/restituerunt } \\
\hline $\begin{array}{l}\text { [viam] q[u]ae [ducit a Karalibus(?) S]ul[ci]s } \\
\text { [vetus]tate [c] orruptam restituit }\end{array}$ & $98-117$ & Epigraphica 76, 2014, 545 & Villamassargia \\
\hline $\begin{array}{l}\text { [viam quae] a Karalibus [Olbiae] ducit vetustate } \\
\text { [collap]sa[m] restituit }\end{array}$ & 220 & $A E 1990,469$ & Code \\
\hline $\begin{array}{l}\text { bia(m) qu(a)e duc(it) a Karalib(us) Olbiae } \\
\text { ve[t]ust(ate) corrumpta }(\mathrm{m}) \text { restituit }\end{array}$ & 235 & $A E 1973,276=1977,346$ & Bonorva \\
\hline $\begin{array}{l}\text { viam quae ducit Turr[em ---] vetustate } \\
\text { corruptam restituit }\end{array}$ & $235-238$ & CIL X 8017 & Bonorva \\
\hline $\begin{array}{l}\text { via }(\mathrm{m}) \mathrm{qu}(\mathrm{a}) \mathrm{e} \text { adducet a Karalibus Olvi }(\mathrm{a}) \mathrm{e} \\
\text { su(a)e vetustate corrupta }(\mathrm{m}) \text { restitui }[\mathrm{t}]\end{array}$ & 236 & $E E$ VIII 1, $798=A E 1975,466$ & $\begin{array}{l}\text { Terranova } \\
\text { Pausania }\end{array}$ \\
\hline $\begin{array}{l}\text { viam qu(a)e duc[it a Kara }] \text { li[b(us)] Olviae } \\
\text { vetustate corrupta(m) restitu[i]t }\end{array}$ & 244 & MSardegna 8 & Bonorva \\
\hline $\begin{array}{l}\text { vi[a]m quae ducit }[\mathrm{a} T] \text { harros } \mathrm{C}[\mathrm{ornu}] \mathrm{s} \\
\text { vetustate corrupta re[s]ti[t]uit }\end{array}$ & 244 & CIL X $8009=$ Cornus 19 & Cabras \\
\hline $\begin{array}{l}\text { viam quae a Nora ducit Bitiae vetustate } \\
\text { corrupta restituit }\end{array}$ & 244 & $C I L \times 7996=I L S 5870$ & Cala d'Ostia \\
\hline $\begin{array}{l}\text { viam quae ducit a Nor[a] Bi[t]iae vetus[tate] } \\
\text { corruptam restit[ue]run[t] }\end{array}$ & 244 & CIL X 7997 & Cala d'Ostia \\
\hline $\begin{array}{l}\text { viam qu(a)e ducit Karalibus Olvi(a)e } \\
\text { vetustate corruptam restituit }\end{array}$ & 244 & $A E$ 1977, 345 & Monte Cuiaru \\
\hline $\begin{array}{l}\text { viam quae a Nora ducit Karalibus vetustate } \\
\text { corupta restituit }\end{array}$ & 244 & CIL X 7999 & Nora \\
\hline $\begin{array}{l}\text { viam quae ducit a Karalibus Olviae vetustate } \\
\operatorname{corrupta}(\mathrm{m}) \text { restituit }\end{array}$ & 244 & CIL X 8027 & Oschiri \\
\hline $\begin{array}{l}\text { viam qu(a)e du[cit] a Karalis Olviae betust[ate] } \\
\text { corruptam restituit }\end{array}$ & 244 & MSardegna $1=A E$ 1984, 444 & Silvaru \\
\hline $\begin{array}{l}\text { viam qu(a)e ducit a Turre usque Karalis } \\
\text { vetustatem corruptam restituit }\end{array}$ & $244-247$ & $E E$ VIII $1,743=A E$ 1890, 87 & Buonanaro \\
\hline
\end{tabular}




\begin{tabular}{|c|c|c|c|}
\hline $\begin{array}{l}\text { [viam] qu(a)e ducet [a] Karalibus Olbiae } \\
\text { vetustate [corruptam rest]ituit }\end{array}$ & $247 / 248$ & $E E$ VIII $1,772=A E 1889,27$ & $\begin{array}{l}\text { Terranova } \\
\text { Pausania }\end{array}$ \\
\hline $\begin{array}{l}\text { vi[a]m quae ducit a Nora [Bitiae?] vetustate } \\
\text { [co]rruptam restituerunt }\end{array}$ & 248 & EE VIII 1, 739 & Nora \\
\hline $\begin{array}{l}\text { viam quae ducit a Nora Karalib(us) vetustate } \\
\text { cor[r]u[p]tam restituerunt }\end{array}$ & 248 & $C I L \times 8001=I L S 511$ & Orri \\
\hline $\begin{array}{l}\text { viam qu[ae ducit a Karalibus] Olvi(a)e v[etusta- } \\
\text { te corruptam restituerunt] }\end{array}$ & $250 / 251$ & MSardegna $6=A E 1984,448$ & Code \\
\hline $\begin{array}{l}\text { [viam quae du]cit a Karalis Vl[biae vet(ustate) } \\
\text { corr(uptam)] restituerunt }\end{array}$ & $250 / 251$ & $\begin{array}{l}\text { ILSard I } 385=\text { MSardegna } 4 \\
=A E 1975,467\end{array}$ & Padronu \\
\hline $\begin{array}{l}\text { biam [qua]e [ducit] a Kar(alibus) Olvi(a)e b[e- } \\
\text { tust(ate) corr(uptam)] restituer(unt) }\end{array}$ & $250-253$ & MSardegna $5=A E$ 1984, 447 & Code \\
\hline $\begin{array}{l}\text { viam qu(a)e a Karalibus Olbiae }[\mathrm{du}] \text { cit vetustate } \\
\text { consun(ptam) }[\mathrm{r}] \text { estituerunt }\end{array}$ & 251 & $E E$ VIII 1, $773=A E 1889,26$ & $\begin{array}{l}\text { Terranova } \\
\text { Pausania }\end{array}$ \\
\hline $\begin{array}{l}\text { viam q(uae) d(ucit) a Tu(rre) K(arales) v(etu- } \\
\text { state) c(orruptam) res[tit(uit)] }\end{array}$ & 253 & ILSard I $383=A E$ 1939, 140 & Code \\
\hline $\begin{array}{l}\text { [viam quae ducit a Karalib(us) Ol]bi(a)e } \\
\text { vetustate cor[ruptam restituit] }\end{array}$ & $253 / 254$ & EE VIII 1,751 & Lipparaggia \\
\hline $\begin{array}{l}\text { viam quae ducit a Nora Karalibus vetustate } \\
\text { corruptam restituit }\end{array}$ & $253 / 254 ?$ & $C I L \times 8000$ & Nora \\
\hline $\begin{array}{l}\text { viam quae ducit a Karalibus [Olbiae vet] ustate } \\
\text { corrupta restituerunt }\end{array}$ & $253 / 254$ & $C I L \mathrm{X} 8033$ (p. 1020) = EE VIII 1, 746 & Olbia \\
\hline $\begin{array}{l}\text { [via quae] a Karalibus [ducit Olbiae vetustate] } \\
\text { consum(p)ta [---] }\end{array}$ & $253 / 254$ & $E E$ VIII $1,781=A E 1889,31=32$ & $\begin{array}{l}\text { Terranova } \\
\text { Pausania }\end{array}$ \\
\hline $\begin{array}{l}\text { [viam quae ducit] a Karali(bu)s Olbiae } \\
\text { [vetustate] consunpta }(\mathrm{m})\end{array}$ & $253 / 254$ & EE VIII 1,782 & $\begin{array}{l}\text { Terranova } \\
\text { Pausania }\end{array}$ \\
\hline $\begin{array}{l}\text { viam quae duc[it a Karalibus] Olb[iae] vet(usta- } \\
\text { te) cor[ruptam restituerunt] }\end{array}$ & $253-257$ & MSardegna $2=A E$ 1984, 445 & Silvaru \\
\hline $\begin{array}{l}\text { viam quae ducit a Karalibus [Olbiae vet] ustate } \\
\text { corrupta }(\mathrm{m}) \text { restituerunt }\end{array}$ & $253-257$ & ILSard I 389 & $\begin{array}{l}\text { Terranova } \\
\text { Pausania }\end{array}$ \\
\hline $\begin{array}{l}\text { viam qu(a)e duc[it a] Karalibus Olbi[ae] } \\
\text { betustate consump[tam] }\end{array}$ & $253-260$ & $E E$ VIII 1, $795=A E 1889,23$ & $\begin{array}{l}\text { Terranova } \\
\text { Pausania }\end{array}$ \\
\hline $\begin{array}{l}\text { viam [quae] ducit a Karalibus Olviae vetus[tate] } \\
\text { corrupta }(\mathrm{m}) \text { restituerunt }\end{array}$ & $253-264$ & $E E$ VIII 1, $774=A E 1889,29$ & $\begin{array}{l}\text { Terranova } \\
\text { Pausania }\end{array}$ \\
\hline $\begin{array}{l}\mathrm{b} \text { [iam quae Karalibus ducit] } \\
\mathrm{O}[\text { lviae vetust]ate corr[uptam restituit] }\end{array}$ & $257 ?$ & CIL X 8028 & $\begin{array}{l}\text { Terranova } \\
\text { Pausania }\end{array}$ \\
\hline $\begin{array}{l}\text { viam] qu(a)e ducit a Karalib(us) Olbi(a)e cor- } \\
\text { rupta[m restituit] }\end{array}$ & $257 ?$ & EE VIII 1,762 & $\begin{array}{l}\text { Terranova } \\
\text { Pausania }\end{array}$ \\
\hline $\begin{array}{l}\operatorname{via}(\mathrm{m}) \text { quae ducit a } \mathrm{K}(\mathrm{a}) \text { ralibus } \mathrm{Ol}[\text { biam] cor- } \\
\operatorname{rupta}(\mathrm{m}) \text { restit(uit) }\end{array}$ & $257 ?$ & $\begin{array}{l}E E \text { VIII } 1,770=I L S 538 \\
=A E 1889,37\end{array}$ & $\begin{array}{l}\text { Terranova } \\
\text { Pausania }\end{array}$ \\
\hline $\begin{array}{l}\text { viam qu(a)e duc(it) a Kar(alibus) Olb(iae) } \\
\text { vetust }\{\mathrm{i}\}(\text { ate }) \text { corr(uptam) rest(ituit) }\end{array}$ & 270 & MSardegna $3=A E$ 1984, 446 & Silvaru \\
\hline $\begin{array}{l}\text { viam [quae] ducet a Kara[lib(us)] Olbiae ve- } \\
\text { tu[state] corrupta }(\mathrm{m}) \text { resti[tu] it }\end{array}$ & $270-275$ & EE VIII 1,775 & $\begin{array}{l}\text { Terranova } \\
\text { Pausania }\end{array}$ \\
\hline $\begin{array}{l}\text { viam [quae] ducit a Karalib(us) Olb[iae] } \\
\text { vetustate corrupta restituente }\end{array}$ & $270-275$ & $E E$ VIII 1, $796=A E 1889,22$ & $\begin{array}{l}\text { Terranova } \\
\text { Pausania }\end{array}$ \\
\hline $\begin{array}{l}\text { [viam] quae ducet a Karalibus Olvi(a)e } \\
{[\text { vetu]state corrupta }(\mathrm{m}) \text { restituente }}\end{array}$ & $282 ?$ & $E E$ VIII 1, $776=A E$ 1889, 36 & $\begin{array}{l}\text { Terranova } \\
\text { Pausania }\end{array}$ \\
\hline $\begin{array}{l}\operatorname{via}(\mathrm{m}) \mathrm{qu}(\mathrm{a}) \mathrm{e} \text { ducit a Kar(alibus) Olbia(e) } \\
\text { vet(ustate) co(rruptam) restituit }\end{array}$ & $282 / 283$ & $E E$ VIII 1, $757=A E 1889,39$ & $\begin{array}{l}\text { Terranova } \\
\text { Pausania }\end{array}$ \\
\hline $\begin{array}{l}\text { viam quae a [Karalibus ducit Olb(iam)] } \\
\text { vetustate corruptam restituit }\end{array}$ & 3.Jh. & $C I L \mathrm{X} 8026=A E 2009,451$ & Valenza \\
\hline
\end{tabular}




\begin{tabular}{|c|c|c|c|}
\hline $\begin{array}{l}\operatorname{via}(\mathrm{m}) \text { quae } \mathrm{du}[\mathrm{cit}] \text { a }[\mathrm{K}] \mathrm{a}[\mathrm{r}] \mathrm{alib}(\mathrm{us}) \text { Olvi[ae] } \\
\text { [vetust(ate) c]or(r) }\{\{\mathrm{m}\}[\mathrm{p}][\operatorname{tam}] \text { res(tituente) }\end{array}$ & $305 / 306$ & MSardegna $7=A E$ 1984, 449 & Code \\
\hline $\begin{array}{l}\text { bia }(\mathrm{m}) \mathrm{q}[\mathrm{uae} \mathrm{du}] \mathrm{cit} \text { Karalib(us) Tur[res] } \\
\text { vetustate corrupta[m re]stituit }\end{array}$ & $?$ & CIL X 8019 & Bonorva \\
\hline viam [---] Olbiae [---] restituerun[t] & $?$ & EE VIII 1,754 & Lipparaggia \\
\hline $\begin{array}{l}\text { viam [q]uae a Karalis [ducit] vetustate } \\
\text { c[orru]ptam r[estituit] }\end{array}$ & $?$ & CIL X 8031 & Olbia \\
\hline $\begin{array}{l}\text { [viam] quae adduc[it Kara]libus Olbi(a)e } \\
\text { [vetus]tate corrup[tam] restitu[it] }\end{array}$ & $?$ & ILSard I 386 & Olbia \\
\hline $\begin{array}{l}\text { vi[am] qu(a)e ducit a Karalibus Olbiae betus[ta- } \\
\text { te corruptam] restitu[it] }\end{array}$ & $?$ & EE VIII 1, 791 & Puzzolu \\
\hline $\begin{array}{l}\text { [viam] quae ducit [a] Karalibus Olb(iae) } \\
\text { betustate cor(ruptam) rest[ituit](?) }\end{array}$ & $?$ & EE VIII 1, 794 & Puzzolu \\
\hline $\begin{array}{l}\text { vi[am qua]e ducit a Karali(bus) corrupta(m) } \\
\text { restituente }\end{array}$ & $?$ & EE VIII 1, 761 & $\begin{array}{l}\text { Terranova } \\
\text { Pausania }\end{array}$ \\
\hline \multicolumn{4}{|l|}{ Weitere einzeln auftretende Formulare } \\
\hline $\begin{array}{l}\text { [viam --- vet] ustate temporis desid[iaque } \\
\text { priorum corruptam ad s]plendorem pristinum } \\
\text { res[tituerit] }\end{array}$ & $312-337$ & CIL VI 1223 (p. 4336) & Roma \\
\hline $\begin{array}{l}\text { murum ad defension }(\mathrm{em}) \text { viae vetustate } \\
\text { conlabsum restituerunt }\end{array}$ & 201 & CIL IX $5980=$ X $6908=I L S 5858$ & $\begin{array}{c}\text { Capua } \\
\text { (regio II) }\end{array}$ \\
\hline $\begin{array}{l}\text { viam Mactorinam longa vetustate resciss(am) } \\
\text { pecunia sua restituit }\end{array}$ & $31-70$ & SupIt II V, $13=A E$ 1919, 64 & $\begin{array}{l}\text { Velitrae } \\
\text { (regio II) }\end{array}$ \\
\hline $\begin{array}{l}\text { viam Aemiliam vetustate dilapsam operib(us) } \\
\text { ampliatis restituendam cur(avit) }\end{array}$ & $143 / 364-367$ & $\begin{array}{l}\text { CIL XI } 6664=I L S 5824 \\
=\text { InscrIt VII 1, } 117\end{array}$ & $\begin{array}{l}\text { Colle Salvetti } \\
\text { (regio VII) }\end{array}$ \\
\hline $\begin{array}{l}\text { viam Augustam a porta Cimina usque ad } \\
\text { Anniam et viam sacram a chalcidico ad lucum } \\
\text { Iunon(is) Curritis vetustate consumptas a novo } \\
\text { restituerunt }\end{array}$ & $?$ & CIL XI 3126 (p. 1323) & $\begin{array}{l}\text { Falerii Novi } \\
\text { (regio VII) }\end{array}$ \\
\hline $\begin{array}{l}\mathrm{v}[\mathrm{i}] \text { as }[\mathrm{i}] \mathrm{n} \text { ru[i]nam vet[u]sta[te }] \\
\mathrm{c}[\mathrm{o}] \mathrm{n}[\mathrm{l}] \mathrm{ab}[\mathrm{sas}] \mathrm{r}[\mathrm{e}] \mathrm{sti}[\mathrm{tuit}]\end{array}$ & $210 / 215$ & RIB I 2228 & $\begin{array}{l}\text { Clausentum } \\
\text { (Britannia) }\end{array}$ \\
\hline $\begin{array}{l}\text { viam Tauri vetustate [conl]apsam conplanatis } \\
\text { monti[bus e]t caesis rupibus ac dilata[tis } \\
\text { i]tineribus cum pontibus institutis restituit }\end{array}$ & $216-217$ & $\begin{array}{l}I K \operatorname{LV} 1,132=R R M A M \text { I } 61=\text { II } 1,26 \\
=\text { III 3, } 166=A E 1969 / 70,607\end{array}$ & $\begin{array}{c}\text { Tyana } \\
\text { (Cappadocia) }\end{array}$ \\
\hline $\begin{array}{l}\text { [viam Apamea Nicae }] \mathrm{a}[\mathrm{m} \text { collapsa]m vetustate } \\
\text { restituit muniendam curavit }\end{array}$ & $58 / 59$ & $\begin{array}{l}\text { CIL III } 346(\text { p. 976) = CIG } 3743 \\
=I K \operatorname{IX~} 13\end{array}$ & $\begin{array}{l}\text { Sarikaya } \\
\text { (Pontus et } \\
\text { Bithynia) }\end{array}$ \\
\hline $\begin{array}{l}\text { viam per Alpes Numidicas vetustate } \\
\text { inter[r]uptam ponti[b]us denuo fac[ti]s } \\
\text { paludibus siccatis labibus confirmatis } \\
\text { res }\{\text { s\}tituit }\end{array}$ & 152 & ILAlg I $3875=I L S 9374=A E$ 1904, 21 & $\begin{array}{l}\text { Ain Berda } \\
\text { (Africa } \\
\text { proconsularis) }\end{array}$ \\
\hline
\end{tabular}


Liste 2: Longa incuria und longa intermissio als Grund für die Erneuerung von Straßen in Nordafrika und Makedonien (sortiert nach Grund/Provinz, Fundort).

Seznam 2: Longa incuria in longa intermissio kot razlog za obnovo cest v provincah Prokonzulska Afrika in Makedonija (razvrstitev po razlogu/provinci, najdišču).

\begin{tabular}{|c|c|c|c|}
\hline Grund & Datierung & Beleg & Fundort \\
\hline \multicolumn{4}{|l|}{ Africa proconsularis: longar incuria } \\
\hline $\begin{array}{l}\text { [---] pontes ve[tustate di]lapsos et iter } 1 \text { [onga in] curia } \\
\text { corrup[tum resti] tuerunt et pro [s]ua [inf] atigabili } \\
\text { provide[ntia pe]rvium commea[ntibus] reddiderunt }\end{array}$ & 237 & $\begin{array}{l}\text { ILAlg I } 3989 \\
=A E 1909,233\end{array}$ & Derirat \\
\hline $\begin{array}{l}\text { [pontes vet] ust[ate conlapsos et iter longa incuria perditum } \\
\text { restituerunt et pro sua infatig]abil[i providentia per]vium } \\
\text { com[me]antibus redd(id)erunt }\end{array}$ & 237 & $\begin{array}{l}\text { CIL VIII } 10021 \text { (p. 2081) } \\
=\text { ILAPr } 654 \\
=\text { ILTun } 1721\end{array}$ & $\begin{array}{l}\text { Fum Es } \\
\text { Somma }\end{array}$ \\
\hline $\begin{array}{l}\text { [po]ntes vetustat[e con]labsos et [iter long] incuria } \\
\text { [perdi]tum re[stituerunt] et pro [sua infatig]abili } \\
\text { [provident]ia pervium [com]meantibus redderunt }\end{array}$ & 237 & $\begin{array}{l}\text { CIL VIII } 10025=21920 \\
=I L A P r 654\end{array}$ & $\begin{array}{l}\text { Hanshir as } \\
\text { Saqy }\end{array}$ \\
\hline $\begin{array}{l}\text { pontes vetu(s)tate delapsos et iter longa iniuria } \\
\text { cor(r)uptum restituerunt sua infatigabili providentia } \\
\text { pervium commeantibus reddiderunt }\end{array}$ & 237 & ВСТH 1912, CLXXXIII & $\begin{array}{l}\text { Lepcis } \\
\text { Magna }\end{array}$ \\
\hline $\begin{array}{l}\text { [pontes vetus] tate dilap[sos et iter lon]ga [incuria } \\
\text { praeruptum] r[estituerunt et pro sua] infatigabili } \\
\text { providenttia pervium commenantibus reddiderunt }\end{array}$ & 237 & $A E 2002,1663$ & $\begin{array}{l}\text { Lepcis } \\
\text { Minor }\end{array}$ \\
\hline $\begin{array}{l}\text { pontes vetus }\{s\} \text { tate dilapsos et iter longa incuria } \\
\text { corruptum restituerunt et pro sua infatigabili providentia } \\
\text { pervium commeantibus reddiderunt }\end{array}$ & 237 & $\begin{array}{l}\text { BCTH } 1908, \mathrm{CCV} \\
=\text { ILAfr } 661 \\
=\text { AE } 2007,1713\end{array}$ & Masclianae \\
\hline $\begin{array}{l}\text { [pontes vetus] tate dilap[sos et iter lon]ga [incuria } \\
\text { praeruptum] r[estituerunt providentia] }\end{array}$ & 237 & AfrRom 14/3, 1704 & Ruspina \\
\hline $\begin{array}{l}\text { pontes vetustate conlabsos et iter longa incuria corruptum } \\
\text { restituerunt et pro sua infatigabili (p)rovidentia pervium } \\
\text { commeantibus reddiderunt }\end{array}$ & 237 & $A E 2003,1972$ & Sufes \\
\hline $\begin{array}{l}\text { pontes vetu(s)tate delapsos et iter longa iniuria corruptum } \\
\text { restituerun(t) sua infaticabili providentia pervium } \\
\text { commeantibus reddiderunt }\end{array}$ & 237 & $\begin{array}{l}\text { IRT } 924 \\
=A E 1912,23=1926,138\end{array}$ & $\begin{array}{l}\text { Wadi az } \\
\text { Zannad }\end{array}$ \\
\hline $\begin{array}{l}\text { viam a Karthagine usque ad fines Numidiae provinciae } \\
\text { longa in[c]ur[i]a corruptam atque dilabsam restituerunt }\end{array}$ & 237 & CIL VIII 22123 & $\begin{array}{l}\text { Sidi Bou } \\
\text { Garnoug }\end{array}$ \\
\hline $\begin{array}{l}\text { viam a Karthag(ine) usque ad fines Numidiae provinc(iae) } \\
\text { longa incuria corruptam adq(ue) dilapsam restituerunt }\end{array}$ & 237 & CIL VIII $10083=22073$ & Sidi Bu Atila \\
\hline $\begin{array}{l}\text { via }[\mathrm{m}] \operatorname{Kar}[\mathrm{th}] \text { agine usque ad fine }[\mathrm{s}] \text { Numidiae } \\
\mathrm{p}[\mathrm{rovi}] \mathrm{n}[\mathrm{c}] \text { iae longa incuria corruptam atque dilap[sa]m } \\
\mathrm{r}[\text { estituer]un[t] }\end{array}$ & 237 & $\begin{array}{l}\text { BCTH 1908, CLXII } \\
=\text { CXCII }\end{array}$ & Tichilla \\
\hline $\begin{array}{l}\text { viam a Karthagine usque ad fines Numidiae provinciae } \\
\text { longa incuria corruptam adque dilapsam restituerunt }\end{array}$ & 237 & $\begin{array}{l}\text { CIL VIII } 10047 \text { (p. 2092) } \\
=\text { ILS } 488\end{array}$ & Tunes \\
\hline $\begin{array}{l}\text { viam a Karthag(ine) usque ad fines Numidiae provinciae } \\
\text { longa incuria corruptam atq(ue) dilapsam restituerunt }\end{array}$ & 237 & ВСТH 1907 CCXXI & Uthina \\
\hline $\begin{array}{l}\text { [viam a] Karthagine [usque ad] fines Numid[iae] provinciae } \\
\text { [longa] incuria co[rrupta]m adque [dilap]sam restitu[e]runt }\end{array}$ & 237 & $\begin{array}{l}\text { CIL VIII } 22020 \\
=\text { ILTun } 1732\end{array}$ & Zezia \\
\hline \multicolumn{4}{|l|}{ Macedonia: longa intermissio } \\
\hline $\begin{array}{l}\text { [vi]am a Dyrrachi(o) usque Acontisma per provinciam } \\
\text { Macedoniam longa intermissione neglectam } \\
\text { restitue[nd] am curavit }\end{array}$ & 112 & $\begin{array}{l}\text { Philippi } 414 \\
=\text { AE } 1936,51 \\
=1993,1401\end{array}$ & Philippi \\
\hline $\begin{array}{l}\text { viam a Dyrrac(hio) usq(ue) Neapoli(m) per provinciam } \\
\text { Macedoniam longa intermissione neglect(am) restituendam } \\
\text { curavit }\end{array}$ & 112 & $\begin{array}{l}\text { Philippi } 715 \\
=I G \times 2,1,1012 \\
=A E 1936,52\end{array}$ & Thessalonica \\
\hline
\end{tabular}


Liste 3: Weitere regional- und zeittypische Erneuerungsformulare ohne nähere Angabe von Gründen (sortiert nach Grund/Provinz, Fundort).

Seznam 3: Druge regionalne in časovno opredeljive formulacije za obnovo cest brez natančnejših razlogov za obnovo (razvrstitev po formulaciji/provinci, najdišču).

\begin{tabular}{|c|c|c|c|}
\hline Grund & Datierung & Beleg & Fundort \\
\hline \multicolumn{4}{|l|}{ Apulia et Calabria } \\
\hline viam Herculiam ad pristinam faciem restituit & 311 & CIL IX $6067=$ X 6972 & $\begin{array}{c}\text { Castel } \\
\text { Lagopesole }\end{array}$ \\
\hline $\begin{array}{l}\text { viam Herculeam [a]d pristinam [f]aciem } \\
\text { restituit }\end{array}$ & 311 & $C I L$ IX $6066=\mathrm{X} 6971=I L S 670$ & Venusia \\
\hline viam Herculiam ad pristinam faciem restituit & 311 & CIL IX 6059 = X 6964 & Zungoli \\
\hline \multicolumn{4}{|l|}{ Cilicia } \\
\hline $\begin{array}{l}\text { vi[am] et [pontes a Pylis usque ad } \\
\text { Ale]xandr[iam ex inte]gro [restituit] }\end{array}$ & $222 / 223$ & $R R M A M$ I app. 3 & Gulek Bogazi \\
\hline $\begin{array}{l}\text { viam et [ponte]s a Pylis usq[ue ad] } \\
\text { Alexa[n]dream ex in[te]gro restituit }\end{array}$ & $222 / 223$ & $\begin{array}{l}\text { CIL III } 12119=14177,12 \\
=I K \text { LV } 1,136=\text { RRMAM I app. } 2 \\
=A E 1899,81\end{array}$ & Gulek Bogazi \\
\hline $\begin{array}{l}\text { viam [et] pontes a Pu[l]is usque ad } \\
\text { [Alexan]driam ex integro [res]ti[tuit] }\end{array}$ & $222 / 223$ & $C I L$ III $226($ p. 974) = RRMAM I 65a & Mopsuestia \\
\hline \multicolumn{4}{|l|}{ Noricum } \\
\hline $\begin{array}{l}\text { pontes refeceru(n)t [et vias] munierunt (et) } \\
\text { milia[ria] restituerunt }\end{array}$ & 236 & $\begin{array}{l}\text { CIL XVII 4, 1, 76 = 4, 2, p. } 125 \\
=A E 1973,389\end{array}$ & Comagena \\
\hline $\begin{array}{l}\text { pontes refecerunt et vias munierunt et } \\
\text { miliaria restituerunt }\end{array}$ & 236 & CIL XVII 4, 1, $91=4,2$, p. 125 & Iuvavum \\
\hline $\begin{array}{l}\text { pontes refecerunt et vias munierunt et } \\
\text { miliaria restituerunt }\end{array}$ & 236 & $\begin{array}{l}\text { CIL III } 14110 \\
=\text { XVII } 4,1,82=4,2 \text {, p. } 125\end{array}$ & Ovilava \\
\hline \multicolumn{4}{|l|}{ Palaestina } \\
\hline vias et pontes restituit & 213 & $A E 1948,152$ & Bar el-Kharuq \\
\hline vias et pontes restituit & 213 & CIL III 14155,16 = AE 1899, 217 & Eleutheropolis \\
\hline vias et pontes restituit & 213 & $A E 1969 / 70,624$ & Es Souwelih \\
\hline vias et pontes restituit & $?$ & $A E 1905,194$ & Scythopolis \\
\hline vias et pontes restituit & 212 & $A E 1966,497 \mathrm{a}$ & Scythopolis \\
\hline vias et pontes restituit & 213 & $R R J$ I 14 & Scythopolis \\
\hline vias et pontes restituit & 213 & RRJ I 15 & Scythopolis \\
\hline vias et pontes restituit & 213 & RJJ I 16 & Yehezqel \\
\hline \multicolumn{4}{|l|}{ Raetia } \\
\hline vias et pontes restituerunt & 201 & $\begin{array}{l}\text { CIL III } 5987 \text { (p. } 1863,2328,50) \\
=\text { XVII } 4,1,33=4,2, \text { p. } 124 \\
=I B R 470\end{array}$ & Cambodunum \\
\hline vias et pontes restituerunt & 201 & $\begin{array}{l}\text { CIL III } 5992 \\
=\text { XVII } 4,1,38=4,2, \text { p. } 124 \\
=I B R 471\end{array}$ & Eggenthal \\
\hline vias et pontes restituerunt & 201 & $\begin{array}{l}\text { CIL III } 5990 \\
=11982=\text { XVII } 4,1,51=4,2, \text { p. } 124 \\
=I B R 476\end{array}$ & Gilching \\
\hline vias et pontes restituerunt & 201 & $\begin{array}{l}\text { CIL III } 5991 \\
=\text { XVII } 4,1,50=4,2, \text { p. } 124\end{array}$ & Grosshelfendorf \\
\hline vias et pontes restituerunt & 201 & $\begin{array}{l}\text { CIL III } 5993 \\
=\text { XVII } 4,1,39-41=4,2, \text { p. } 124 \\
=I B R 472\end{array}$ & Kaufbeuren \\
\hline
\end{tabular}




\begin{tabular}{|c|c|c|c|}
\hline vias et pontes restituerunt & 201 & CIL XVII 4, 1, $70=4,2$, p. 124 & Kosching \\
\hline vias et pontes restituerunt & 201 & $\begin{array}{l}\text { CIL III } 5996=11985=\text { XVII } 4,1,65 \\
=I B R 490\end{array}$ & $\begin{array}{c}\text { Neuburg } \\
\text { an der Donau }\end{array}$ \\
\hline vias et pontes restituerunt & 201 & $\begin{array}{l}\text { CIL III } 5981=11979 \\
=\text { XVII } 4,1,16=4,2, p .123 \\
=I B R 454\end{array}$ & Veldidena \\
\hline vias et pontes restituerunt & 201 & CIL XVII 4, 1, $17=A E 2002,1085$ & Veldidena \\
\hline vias et pontes restituerunt & 201 & CIL XVII 4, 1, $66=4,2$, p. 124 & $\begin{array}{c}\text { Vicus } \\
\text { Scuttariensium }\end{array}$ \\
\hline vias et pontes restituerunt & 201 & $\begin{array}{l}\text { CIL XVII 4, 1, } 8=4,2, \text { p. } 123 \\
=A E 1982,730=1991,1282\end{array}$ & Vipitenum \\
\hline
\end{tabular}

Liste 4: Viam imbribus et vetustate conlapsam cum pontibus restituit als Grund für die Erneuerung von Straßen in Numidien (sortiert nach Datierung, Fundort, Beleg).

Seznam 4: Viam imbribus et vetustate conlapsam cum pontibus restituit kot razlog za obnovo cest v provinci Numidiji (razvrstitev po dataciji, najdišču, objavi).

\begin{tabular}{|c|c|c|c|}
\hline Grund & Datierung & Beleg & Fundort \\
\hline $\begin{array}{l}\text { viam imbribus et vetustate conlabsam cum } \\
\text { pontibus restituit }\end{array}$ & 218 & CIL VIII 10309 (p. 2138) & Oued Smendou \\
\hline $\begin{array}{l}\text { viam imbribus et vetust[ate] conlaps[am] cum } \\
\text { pontibus restituit }\end{array}$ & 219 & CIL VIII $10304=I L S 471$ & Cirta \\
\hline $\begin{array}{l}\text { viam imbribus et vetustate conlabsam cum } \\
\text { pontibus restituit }\end{array}$ & 220 & CIL VIII 10308 (p. 2138) & Oued Smendou \\
\hline $\begin{array}{l}\mathrm{v}[\mathrm{iam}] \text { imbribus et vetustate conlapsam cum } \\
\text { pontibus restituit }\end{array}$ & 238 & CIL VIII $22371=$ ILS 5869 & Cirta \\
\hline viam imbrib[us] & 238 & CIL VIII $10298=22364$ & Hammet \\
\hline $\begin{array}{l}\text { viam imbribus et vetustate }\{\mathrm{m}\} \text { coniapsam cum } \\
\text { iontibus rdi }[\mathrm{t}] \text { nit }\end{array}$ & 238 & CIL VIII 22372 & Oued Smendou \\
\hline viam imbribus et vetu[state ---] & 245 & CIL VIII 10299 & Cirta \\
\hline $\begin{array}{l}\text { viam imbribus et vetustate conlapsam cum } \\
\text { pontibus restituerunt }\end{array}$ & 245 & CIL VIII 22373 & Oued Smendou \\
\hline $\begin{array}{l}\text { viam imbribus [et vetus]tate conlabsa[m cum] } \\
\text { pontibus res[tituit] }\end{array}$ & 250 & CIL VIII 10318 (p. 2138) & Cloaret \\
\hline $\begin{array}{l}\text { viam imb[ribus et] vetustate [collap]sam cum } \\
\text { pont[ibus] restitui[t] }\end{array}$ & 250 & CIL VIII 10314 & El Arrouch \\
\hline $\begin{array}{l}\text { viam imbribus [et vetustate conlapsam cum } \\
\text { pontibus restituerunt] }\end{array}$ & 252 & CIL VIII 10320 (p. 2138) & Oued Hammam \\
\hline $\begin{array}{l}\text { viam imbribus et vetustate conlapsam cum } \\
\text { pontibus restituerunt }\end{array}$ & 252 & CIL VIII $10323=22365$ & Rusicade \\
\hline $\begin{array}{l}\text { viam imbribus et vetustate [conlap] sam cum } \\
\text { [pontibus] resti[tuit] }\end{array}$ & 283 & CIL VIII 10315 & El Arrouch \\
\hline $\begin{array}{l}\text { [viam imbribu]s et vetus[tate conlapsam] cum } \\
\text { pont[ibus resti]tuit }\end{array}$ & 283 & CIL VIII 10316 & El Arrouch \\
\hline $\begin{array}{l}\text { viam imbribus et vetust[ate] conlabsam cum } \\
\text { [pon]tibus restituit }\end{array}$ & 283 & CIL VIII 22379 & El Arrouch \\
\hline $\begin{array}{l}\text { viam imbribus et vetustate conlapsam cum } \\
\text { pontib[us] restituit }\end{array}$ & $?$ & CIL VIII 10302 (p. 2138) & Cirta \\
\hline
\end{tabular}


Liste 5: Vias torrentibus exhaustas restituit als Grund für die Erneuerung von Straßen in Numidien (sortiert nach Datierung). Seznam 5: Vias torrentibus exhaustas restituit kot razlog za obnovo cest v provinci Numidiji (razvrstitev po dataciji).

\begin{tabular}{|l|c|l|c|}
\hline \multicolumn{1}{|c|}{ Grund } & Datierung & \multicolumn{1}{c|}{ Beleg } & Fundort \\
\hline $\begin{array}{l}\text { vias torrentibus exhaustas restituit ac novis } \\
\text { munitionibus dilatavit }\end{array}$ & 213 & AE 1911, 101 & Cuicul \\
\hline $\begin{array}{l}\text { vias ex(h)austas r[e]stituit ac novis } \\
\text { mun[itio]nib(us) dilatavit }\end{array}$ & 215 & CIL VIII 10335 (p. 2143) ILS 5862 & Bordj Mamra \\
\hline $\begin{array}{l}\text { vias torrentibus exhaustas restituit et novis } \\
\text { munitionibus dilatavit }\end{array}$ & $222-224$ & AE 1912, 155 & Cuicul \\
\hline vias torr[e]ntibus exh[au]stas restituit & $238-244$ & CIL VIII 22399 & Cuicul \\
\hline $\begin{array}{l}\text { vias torrentib(us) exhausias res[tit]uit ac } \\
\text { nov[is] [munitionibus dilavit] }\end{array}$ & 245 & CIL VIII 22397 = ILS 5871 & Fedj Mzala \\
\hline vias torrentibus exhaustas restituit & 253 & ILS 9498 = AE 1911, 104 & Cuicul \\
\hline
\end{tabular}

\section{Razlogi za obnovo cest v luči latinskih napisov na miljnikih}

\section{Povzetek}

Latinski napisi na rimskih miljnikih so doslej služili predvsem kot natančen vir datacij titulatur rimskih cesarjev in njihove gradbene dejavnosti ter vir za rekonstrukcijo cestnih mrež. Članek se osredotoča na primerjalno perspektivo na višji ravni. Avtorica je raziskovala razloge za obnovo cest, ki jih omenjajo napisi na miljnikih. Iz spletne epigrafske baze Clauss-Slaby je zbrala 250 napisov, ${ }^{*}$ na katerih se pojavljata formulaciji viam restituit ali iter restituit (je obnovil cesto/pot). S primerjavo omenjenega zbira je avtorica izluščila epigrafske formulacije ("epigraphic habit"), ki se med seboj razlikujejo po posameznih območjih, kjer so bili miljniki postavljeni. Razlike so vidne v strukturi formulacij napisov, $v$ dataciji miljnikov ter tudi v ukrepih, ki so bili sprejeti ob nastali škodi in uničenju ceste. $\mathrm{V}$ treh izmed štirih primerov je bil razlog za obnovo ceste starost (vetustas). $\mathrm{Na}$ miljniku iz Numidije, datiranem v 3. st. n. št., beremo, da sta bila za slabo stanje ceste kriva dež in starost (imber et vetustas). Kot sporočajo drugi napisi, je bila ta fraza $\mathrm{v}$ provinci Numidiji v rabi kar 65 let. Za omenjeno provinco je izpričana še ena formulacija, in sicer vias cum pontibus restituit; $s$ tem ukrepom je uprava poskušala rešiti problem slabih komunikacijskih poti zaradi vremenskih nevšečnosti: čez namočena oziroma poplavljena območja so postavili mostove, s katerimi so bile ceste ponovno prevozne. Rezultati študije so predstavljeni v obsežnih seznamih 1-5.

* Op. prev.: Najdišča na seznamih ustrezajo navedbam v EDCS. Za napačno (npr. mesto hrambe) ali nepopolno navedene najdiščne podatke miljnikov, odkritih na slovenskem prostoru (glej seznam 1: 3. stran, stolpec Fundort), navajamo popravke po temeljni literaturi: za miljnik CIL III 4617 - Mačkovec pri Novem mestu; za CIL III 4622 Krško polje; za CIL III 4623 - Obrežje; za AE 2006, 1032 - Gorenje Karteljevo.

Prevod: Anja Ragolič

\section{Ulrike Ehmig}

Berlin-Brandenburgische Aka-

demie der Wissenschaften

Corpus Inscriptionum Latinarum

Jägerstraße 22/23,

D-10117 Berlin 0049-30-20370-212

ulrike.ehmig@bbaw.de

https//:orcid.org/0000-0003-1560-9022 